Columbia Law School

Scholarship Archive

\title{
Liberalism and Tort Law: On the Content and Economic Efficiency of a Liberal Common Law of Torts
}

Richard S. Markovits

rmarkovits@mail.law.utexas.edu

Follow this and additional works at: https://scholarship.law.columbia.edu/faculty_scholarship

Part of the Common Law Commons, Law and Society Commons, and the Torts Commons

\section{Recommended Citation}

Richard S. Markovits, Liberalism and Tort Law: On the Content and Economic Efficiency of a Liberal Common Law of Torts, U of TeXas LaW AND Economics Research PaPer No. 41 (2005).

Available at: https://scholarship.law.columbia.edu/faculty_scholarship/1356

This Working Paper is brought to you for free and open access by the Faculty Publications at Scholarship Archive. It has been accepted for inclusion in Faculty Scholarship by an authorized administrator of Scholarship Archive. For more information, please contact scholarshiparchive@law.columbia.edu. 


\title{
THE UNIVERSITY OF TEXAS SCHOOL OF LAW
}

\author{
Law and Economics Working Paper No. 41
}

February 2005

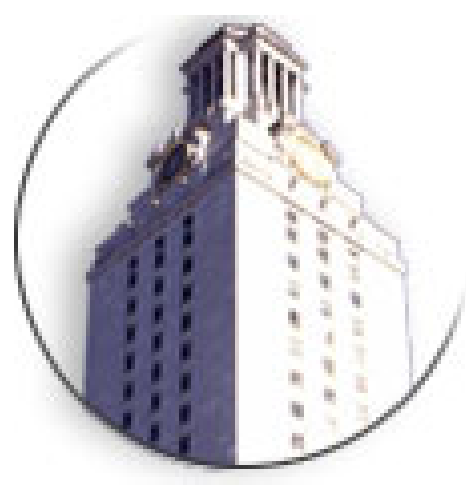

LIBERALISM AND TORT LAW: ON THE CONTENT AND ECONOMIC EFFICIENCY OF A LIBERAL COMMON LAW OF TORTS

\section{Richard S. Markovits}

\section{The University of Texas School of Law}

This paper can be downloaded without charge from the Social Science Research Network Electronic Paper Collection: $\underline{\text { http://ssrn.com/abstract }=670163}$

An index to the working papers in The University of Texas School of Law Working Paper Series is located at http://www.utexas.edu/law/ 


\title{
LIBERALISM AND TORT LAW: ON THE CONTENT AND ECONOMIC EFFICIENCY OF A LIBERAL COMMON LAW OF TORTS
}

(C) 2005 Richard S. Markovits

\begin{abstract}
This Article has three parts. Part I begins by delineating the protocol one should use to determine whether a society is an immoral society, an amoral society, a goal-based society of moral integrity, or a rights-based society of moral integrity (i.e., a society that engages in a bifurcated prescriptive-moral practice that strongly distinguishes moral-rights claims [about the just] from moral-ought claims [about the good], that is committed to the lexical priority of the just over the good, and that fulfills its commitments to some hard-to-specify, requisite extent). Part I then proceeds to outline the protocol one should use to determine the moral norm that any particular rights-based society is committed to using to derive moral-rights conclusions. It next provides an account of the liberal moral norm that I think our rights-based society is committed to instantiating. It argues that this norm commits us to treating all creatures that have the neurological prerequisites to lead a life of moral integrity (to take their moral obligations seriously and to take seriously as well the dialectical task of choosing a conception of the good and leading a life that is consonant with that conception) with appropriate, equal respect and to showing appropriate, equal concern for such creatures, in part for their welfare as economists understand that concept but primarily for their having a meaningful opportunity to lead a life of moral integrity. Part I concludes by examining the implications of our society's liberal commitments for (1) the tort-related moral duties and rights of its members and participants and (2) the general tort-related duties of its governments and the more specific duties of our society's courts when adjudicating common-law tort cases. This account proceeds from a premise uncongenial to economics that, from the perspective of liberalism, not all effects are commensurable - viz., that any tendency of a choice to deprive moral-rights holders on balance of a meaningful opportunity to lead a life of moral integrity by killing them, depriving them of the neurological prerequisites for leading a life of moral integrity, subjecting them to lifedominating pain, or (perhaps) treating them in ways that substantially undercut their perception
\end{abstract}


that they are the authors of their own lives cannot be offset by any tendency the choice has to increase "mere utility" or "welfare" as economists understand that term. Part I argues inter alia that (1) its claim that ours is a liberal, rights-based society and (2) its account of the implications of that fact for the obligations of our society's members, participants, and common-law judges provide a normative grounding both for something like the Hand formula for negligence and for the common law's treatment of ultrahazardous activities. More specifically, Part 1 argues that liberalism implies that (1) something like the Hand formula for negligence is the appropriate standard for determining tort liability for possibly-tortious choices made by individuals who knew or should have known that their choices should be expected to impose net equivalent-dollar losses on others that reflect "mere-utility losses" the relevant victims sustained and (2) individuals who made possibly-tortious choices they knew or should have known should be expected to disserve the interests of some others in having a meaningful opportunity to lead a life of moral integrity are liable in tort unless their choices served the on-balance interests of the society's members and participants in having an opportunity to lead such a life.

Part 2 then examines whether a common law of torts that seeks solely to secure liberal corrective-justice rights will be economically efficient. More specifically, Part 2 delineates and explores twelve reasons why the correct resolution of a liberal corrective-justice claim may not be economically efficient.

Finally, Part 3 identifies and analyzes the moral status (inter alia, the moral legitimacy) and likely generic desirability (moral-rights considerations aside) of the various possible noncommon-law components of the positive tort law of a liberal, rights-based State-i.e., of its relevant constitutional law, statutory law, administrative regulations, and truly-judge-made law. 


\title{
LIBERALISM AND TORT LAW: ON THE CONTENT AND ECONOMIC EFFICIENCY OF A LIBERAL COMMON LAW OF TORTS
}

\author{
(C) 2005 Richard S. Markovits
}

This Article analyzes

(1) the proper way to determine the general moral character, the general moral type, and the specific moral commitments of any society;

(2) the general content of liberal moral commitments;

(3) the tort-law-related corollaries of a liberal, rights-based society's commitmentsi.e., the implications of liberalism for the moral and legal tort-related rights and/or obligations of a liberal, rights-based society's members, participants, and governments,

(4) the reasons why judges in those liberal, rights-based societies that have a common law of torts are obligated to resolve common-law tort cases in favor of a plaintiff if and only if he has a corrective-justice ${ }^{1}$-based right of redress against the defendant (who had harmed him wrongfully by making a tortious choice that violated the defendant's liberal moral obligations to the plaintiff);

(5) the economic efficiency of the common law of torts of a liberal, rights-based society; and

(6) the moral status from a liberal perspective and the generic desirability (moralrights considerations aside) of the various possible non-common-law components of the tort law of a liberal, rights-based society.

The Article has three parts. Part 1 focuses on the first four issues in the preceding list.

Part 2 delineates and explains twelve reasons why a body of tort law that is exclusively oriented toward securing wronged tort victims' corrective-justice tort rights may not be economically efficient. And Part 3 analyzes the relationship between the possible constitutional, statutory,

1 In standard usage, "corrective justice" requires that "individuals who are responsible for the wrongful losses of others have a duty to repair the losses." See Jules Coleman, Tort Law and Tort Theory: Preliminary Reflections on Method in Philosophy and the Law of Torts (Gerald Postema, ed.) 183, 184 (2001). In this study, I will use the expression "corrective-justice-related" duties to refer not only to this duty of repair but also to the duty of members of a rights-based State not to commit the wrongs that can give rise to a corrective-justice duty of repair and to the duties of the government(s) of a rights-based State to prevent such wrongs, to secure compensation for victims of such wrongs, and perhaps to prevent those who have committed such wrongs from profiting from them. 
administrative-regulation, and judicially-legislated components of the positive tort law of a liberal, rights-based society and that society's moral commitments and offers some brief comments on the relative generic attractiveness (rights-consideration aside) of the noncorrective-justice-oriented legislation that legislatures, administrative agencies, and judges are likely to create.

Before proceeding, I want to make four preliminary observations. First, many philosophically-oriented analyses of tort law focus on formal elements of corrective justice without ever discussing the grounding or content of the substantive moral right whose violation gives rise to a concrete corrective-justice claim. This Article focuses primarily on the grounding and content of the moral rights whose existence corrective-justice claims presuppose.

Second, although the moral and possible legal tort-related corollaries of liberalism will clearly be of more interest if, as I claim, ours is a liberal, rights-based society, one might be interested in liberalism's tort-related implications even if no actual society were a liberal, rightsbased society. Readers who reject my conclusions about our society’s general moral type, general moral character, and specific moral commitments and/or my claims about those conclusions' implications for the internally-right answer to some legal-rights questions may therefore still be interested in the Article's analyses of (1) the implications of liberalism for the way in which private actors should behave in situations in which their choices might be tortious, (2) the implications of liberalism for the choices that common-law judges and other officials of a liberal, rights-based State are obligated to make, and (3) the reasons why the tort-related private and State choices that liberalism recommends may not be allocatively efficient.

Third, some readers may understandably be troubled by my handling of the various fits and non-fits between (1) my accounts of (A) liberalism and (B) its tort-related corollaries on the one hand and (2)(A) the positive common law of torts in the United States ${ }^{2}$ and (B) various normative positions at least some Americans take on related issues on the other hand. Such readers may complain that I am trying to have it both ways. Thus, in the one direction, I proudly announce the fact that my account of liberalism fits various legal doctrines and social beliefs. For example, I trumpet the fact that my account of liberalism's implications for the moral obligations of potential injurers in a liberal, rights-based society who are considering choices that 
may harm others in ways that do not deprive them of a meaningful opportunity to lead a life of moral integrity (that may impose what I will call "mere utility" losses on them) not only fits (at least a cleaned-up version of) the Hand formula for negligence but provides a moral grounding for that legal doctrine. Similarly, I take some pride in the fact that my account of liberalism's implications for the moral obligations of potential injurers who are considering choices that may harm others in ways that would deprive them of a meaningful opportunity to lead a life of moral integrity would provide a normative justification for the RESTATEMENT (SECOND's) conclusion about the liability of owners of "ultrahazardous activities." At least, my account of liberalism will ground this RESTATEMENT conclusion if the key expressions in the relevant RESTATEMENT provisions ("abnormally dangerous" and "low value" to the community) were given plausible though non-standard interpretations-i.e., if the RESTATEMENT provision is read to state that injurers whose (ultrahazardous) activities are "abnormally dangerous" in the sense of creating a risk that they may deprive someone of the opportunity to lead a life of moral integrity are liable for the losses such activities cause even if their avoidance-move rejections would not be deemed negligent by the conventional Hand formula unless their choices did not on balance disserve the interest of the relevant population in having such an opportunity (were otherwise of sufficiently "high value" to the community in the sense of promoting such opportunities in other ways to make them morally desirable when evaluated through the application of such an opportunity-tolead-a-life-of-moral-integrity metric). And again, I take some comfort in the fact that the selfconception-oriented corollary of liberalism I articulate (which focuses on the importance of individuals' feeling that they are the authors of their own lives) provides a liberal justification for at least some libertarian conclusions about the liberty rights of moral-rights holders.

In the other direction, some readers may feel that I am insufficiently intellectually disturbed by various non-fits between my account of the legal implications of liberalism and our positive law of torts or the more general way in which the governments of our society have responded to tort contingencies. If anything, such readers might claim, I treat these non-fits not as evidence against my conclusions about our society's moral commitments and/or their common-law-of-torts corollaries but as evidence of these conclusions' practical importancei.e., argue that the existence of such non-fits enhances the value of my analysis by creating the

\footnotetext{
2 Yes, I know that the law of torts varies from state to state.
} 
possibility that it might lead to improvements in our society's conduct. Although there is something to this accusation, it tells only part of the story. In fact, I do regret these non-fits (1) not just because, as a liberal, I regret the reality they manifest (our society's failure to instantiate liberal norms) but also (2) because I recognize that their existence disfavors either or both my conclusion that our society is a liberal, rights-based society and/or my conclusions about the content of the common law of torts of a liberal, rights-based State and the more general tortrelated obligations of the governments of a liberal, rights-based State.

However, I admit that I find the relevant non-fits less damaging to my position than many readers might, at least on first thought, consider them to be. In part, my assessment of the significance of such non-fits reflects my conclusion that, to be justified, my conclusions about the moral type, moral character, and specific moral commitments of our society need not fit the conduct, beliefs, and perceptions of our society's members and governments perfectly. They need only (1) discounted-fit these facts better than do any alternative conclusions about our society's moral character and specific moral commitments (where the weight of a non-fit is discounted by its explicability-see below) and (2) discounted-fit these facts well enough to justify the conclusion that our society has moral integrity (is a society that has commitments that deserve to be called "moral" and fulfills these commitments well enough to deserve to be called “a society of moral integrity"-see below again). And, in part, my assessment of the damage these non-fits do to my position reflects my conclusion that, although legal realities are relevant to the "empirical” analyses of “discounted fit” on which conclusions about a society's moral type, moral character, and specific moral commitments must be based, such data form only a tiny percentage of the social facts from which such conclusions should be derived. Most of the relevant data relates to the prescriptive-moral claims, arguments, conclusions, perceptions, and conduct that people make, reach, have, and engage in outside of legal fora, frequently when — for transaction-cost-related or other reasons - there is no possibility that a legal claim will ever be made. Legal academics are far too inclined to believe that only arguments and decisions that are made in courts or legislatures are relevant to determining the internally-right answer to a legalrights issue. This Article both argues for and proceeds from a contrary conclusion.

The fourth and final observation I want to make at this juncture relates to the extent of the changes that I think our liberal commitments require us to make in our tort-related conduct. In 
the one direction, I want to point out that — to my mind-our liberal commitments do obligate us to change a good deal not only of our tort law but also of our tort-related conduct. Think, for example, of the number of contemporary decisions that violate the corollary of liberalism (see below) that choices that create the possibility that some member of or participant in our society may lose the opportunity to lead a life of moral integrity (by creating a risk that he may be killed, deprived of the neurological prerequisites for acting as a moral agent, subjected to lifedominating pain, or perhaps induced to reject the belief that he is the author of [and hence is responsible for] his own life) are moral-rights-violative unless the chooser can demonstrate that ex ante he reasonably believed that his choice would not disserve on balance the interest of the relevant creatures in having such an opportunity. More particularly, I want to point out the "radical” implications of liberalism to counter the frequently-made claim that moral arguments that focus on the existing commitments of the society or individuals to which they apply are conservative in that they support the status quo in the special sense of demanding no change in conduct: although that argument would be correct if all individuals and societies lived up to their moral commitments perfectly or (somewhat relatedly) if moral commitments had to be inferred from conduct and were isolated in the sense of not being interconnected, it will not be correct if either (1) moral commitments can be derived through foundationalist argument (see below) and are not always fulfilled or (2) moral commitments are derived from highly-qualified conventionalist argument (see below) that is designed to identify the moral norm that best discounted-fits the relevant empirical realities-a procedure that can yield determinant conclusions in the realistic case in which the relevant data does not perfectly fit the moral norm that it best discounted-fits.

In the other direction, I want to counter the contention of some readers that the corollary of liberalism just articulated would require us to return to a pre-industrial-revolution agricultural society (to abandon all or virtually all technology and revert to some imagined eighteenthcentury village life). For two reasons, this contention is completely unjustified. The first and less important is that it implicitly underestimates the dangerousness of even "pre-industrialrevolution” agricultural labor and the toxicity of even pre-industrial fertilizer and agricultural run-offs. The second and more important reason is that it ignores the fact that a great deal of economic product is required to provide our society's members and participants with the 
nutrition, clothing, housing, medical care, and education that they need to live as long lives as they might under conditions that would give them an opportunity to take their lives morally seriously. Certainly, a significant portion of contemporary Americans do not have the nutrition, clothing, housing, health care, formal education, range of experiences, and other sorts of opportunities with which I think our society's liberal commitments entitle them to be supplied (if it is technologically and economically possible to do so). I am optimistic that we could fulfill this basic obligation of a liberal, rights-based society by redistributing resources and opportunities to the poor and, most importantly, to the children of the poor-that our total product would suffice for this purpose even if it were reduced in the short and medium run (i.e., before the relevant redistributions increased the productivity of the children of the poor and their descendants) by the incentive-effects of the required redistribution. However, I doubt that we could fulfill this obligation without engaging in industrial activities that would put at risk the opportunity of some to lead a life of moral integrity, perhaps regardless of the way in which they were carried out but certainly given the way in which they would be carried out despite the State's efforts to prevent their wrongful execution. It should be noted that this line of argument may legitimate not only economic activities that directly produce the goods and services that significantly contribute to individuals' having a meaningful opportunity to lead a life of moral integrity but also economic activities that produce other goods and services whose availability provides the members of and participants in the society in question with an incentive to produce life-of-moral-integrity-related goods and services. This point is made salient inter alia by the postulate of liberal idealism, which (in the version I will be referencing) asserts that when acting in non-political capacities the members of a liberal, rights-based society do not in general have an obligation to provide others with goods and services that their governments are obligated to secure for them. 
1. The Morally-Legitimate, Internally-Correct Answer to Any Common-Law Legal-Rights Question in the United States

Part 1 argues that (with one possible exception ${ }^{3}$ ) the internally-correct answer to any legal issue that arises in a "common law of torts" case in the United States (the answer that is correct as a matter of American law) is the answer warranted by a liberal conception of corrective justice and explains in some detail the content of that conception of corrective justice. The following argument explains the relationship between the morally-legitimate, internally-right answer to common-law torts-questions in the United States and the liberal conception of torts-related corrective-justice entitlements:

(1) to be morally legitimate, the use of an argument to resolve a legal-rights question or the answer given to a legal-rights question must be consistent with the moral commitments of the society in which the legal analysis is being executed;

(2) except to the extent that a contrary conclusion is warranted by the fact that the relevant society's constitution contains text that is inconsistent with its moral commitments and whose import was properly understood by its ratifiers at the time of ratification, no argument whose use is inconsistent with the moral commitments of a society of moral integrity can ever be legally valid-i.e., can ever count in disputes about the internally-correct resolution of a legal-rights question in that society in a way that is inconsistent with that society's moral commitments - and no answer to a legal-rights question that is inconsistent with such a society's moral commitments can ever be internally correct;

(3) the United States is a liberal, rights-based society of moral integrity;

neither the contemporary Constitution of the United States nor the constitution of any individual state contains text that is relevant to the resolution of any moralrights-related tort-law issue that is inconsistent with our society's moral commitments;

3 The possible exception relates to cases in which a liberal, rights-based State may be obligated to provide a legal entitlement to a victim who cannot establish that, more probably than not, any specific wrongdoer has been a but-for course of his loss to recover some or all of his loss from wrongdoers who may have wrongfully caused his loss and did wrongfully cause someone to suffer the type of loss he suffered. This possibility is explored in the paper on the causation-element of corrective-justice claims to which I have already referred. The issue has arisen in pharmaceutical cases in which the consumer cannot identify the specific company from which he bought a drug that caused him harm that materialized long after his purchase, in some asbestositis cases, in at least one case involving petroleum derivatives, and in a few hand-gun cases. In some of these cases, courts have dealt with this issue by imposing market-share liability on each putative injurer. For a clear presentation of the case-law, see DAN V. DOBBS, THE LAW OF TORTS $\S 176$ at 430-32 (2000). 
(5) the governments of rights-based societies are morally obligated to enforce the moral rights of those for whom they are responsible whenever they can do so without sacrificing the on-balance rights-related interests of those for whom they are responsible;

(6) the governments of the United States need not sacrifice any rights-related interests to enforce the corrective-justice tort-related moral rights of those for whom they are responsible; therefore,

(7) to the extent that the governments of the United States have chosen to fulfill their obligations to secure the corrective-justice rights of the society's members and participants by creating common-law courts that are authorized to discover and legally enforce the corrective-justice-related moral rights of their society's members and participants, those courts are obligated to base their conclusions in common-law cases (including common-law tort cases) in which the parties are asserting moral-rights-related legal rights on moral-rights arguments (on arguments of moral principle) and to reach conclusions in those cases that are consistent with the State's obligation to secure the corrective-justice-related moral rights of the parties. ${ }^{4}$

A. The Moral Type, Moral Character, and Basic Moral-Rights Commitment of the United States

The preceding discussion clearly implies that the moral character, moral type, and moral commitments of the United States determine both (1) the set of arguments that can be legitimately and validly used to determine the content of the common law of torts in the United States and (2) the content of that law. I will now delineate and explain the basis of my conclusions about these issues.

Societies can be placed into three, broad moral-character categories. Some societies are amoral (have no moral commitments); some are immoral (are committed to effectuating some standard or achieving some goal whose effectuation or achievement is immoral-i.e., violates

\footnotetext{
$4 \quad$ This conclusion is consistent with the conclusion that it would be morally legitimate (i.e., consistent with the relevant society's moral commitments) for the legislature of a liberal, rights-based State to authorize courts that also have common-law jurisdiction to apply tort legislation it passed that did not violate the corrective-justicerelated rights of any member of or participant in the society in question. Part III will explore inter alia the moral legitimacy of the legislature of such a State's authorizing courts to enact such tort legislation on their own. At this juncture, I will confine myself to the following observation: even if it would be consistent with such a society's moral commitments for a legislature to authorize courts to enact legislation that would be applied only prospectively, it would clearly be morally impermissible for such a legislature to enact such legislation and apply it retrospectively (or for courts to enact and apply such legislation retrospectively without legislative authorization).
} 
some ineliminable, universally-applicable tenet of morality); and some have moral integrity (are committed to a purported moral norm that is in fact moral and fulfill that commitment to some hard-to-specify, requisite extent). In order to determine whether a particular society is amoral, is immoral, or has moral integrity, it is necessary (1) to identify the decision-standard(s) it purports to use or seems implicitly to use to resolve various issues, (2) to determine whether the identified decision-standards are moral, immoral, or non-moral, and (3) to assess the extent to which its members' and governments' conduct is consistent with the decision-standards they claim to be using or the decision-standards their discourse, perceptions, and conduct imply they are using.

Societies of moral integrity can themselves be divided into two types-rights-based societies and goal-based societies. ${ }^{5}$ The statement that a given culture is rights-based has two predicates. First, members of a rights-based culture engage in two kinds of prescriptive-moral discourse-moral-ought discourse about what an individual or the State morally-ought to do and moral-rights discourse about what an individual or the State is morally obligated to do. Second, in a rights-based culture, an individual cannot excuse or justicize (establish the justness of) a choice that violates someone's moral rights by demonstrating that it was consistent with the personal ultimate values to which the individual subscribed, and the State cannot justicize a choice that violates someone's moral rights by demonstrating that it helped the State achieve one or more goals the State is authorized to pursue. In other words, in a rights-based culture, moralrights claims are strongly distinguished from moral-ought claims, and moral-rights conclusions (and the moral norms on which they are based-hereinafter "moral principles") trump (are lexically prior to) moral-ought conclusions and the moral norms from which they are derived (hereinafter "personal ultimate values”). Of course, nothing in the preceding account of rightsbased cultures denies the reality that most individual and State choices in rights-based cultures do not implicate the moral rights of the non-chooser - that even in rights-based cultures, the only moral issue raised by most choices that have a moral dimension is what the relevant chooser morally-ought to do.

$5 \quad$ Although some would argue that ideal-based societies should be distinguished from goal-based societies and rights-based societies, I would classify ideal-based societies as a subtype of goal-based societies. Similarly, although some would claim that religious-duty-based societies should be classified separately from goal-based societies and rights-based societies, I would classify such societies as a variant of rights-based societies since their 
The statement that a society of moral integrity is goal-based implies that its members do not draw a strong distinction between moral-ought discourse and moral-rights discourse. Although members of a goal-based society may sometimes use moral-rights language, they do so simply to communicate the strength or certainty of their view about what they think morallyought to be done. Correlatively, although goal-based societies may have a category "constitutional rights," these rights are enforced only when doing so enables the State to achieve its preferred goals-i.e., in goal-based societies, goals trump what they (to my mind, misleadingly) call "rights" when the goals and "rights" favor different courses of conduct.

To determine whether a given society of moral integrity is goal-based or rights-based, one must observe its members' prescriptive-moral conduct and discourse and determine

(1) whether they draw a strong distinction between moral-rights claims and moralought claims,

(2) whether they conclude that, when the answer to something they may refer to as a "moral-rights claim" conflicts with the answer that the evaluator would give to the question "what morally-ought to de done," the moral-rights conclusion trumps the moral-ought conclusion, and

(3) whether (relatedly) any individual who (government that) violates what is sometimes called his (its) moral obligations because of his (its) sincere commitment to a particular personal ultimate value (to achieving some goal) is subjected to weighty moral censure on that account.

I assume that there is no single, objectively-true, universally-applicable moral norm on which rights-based societies of moral integrity must be committed to grounding their moralrights-related conduct (or, for that matter, to which goal-based societies of moral integrity must be exclusively committed). Since I believe that an appropriate "empirical" analysis ${ }^{6}$ would

members, like those of rights-based societies, strongly distinguish the right from the good and lexically order the right over the good.

6 As the text implies, my approach to determining the moral commitments of a given society is "highlyqualified" conventionalist. I enquoted the word "empirical” because the highly-qualified conventionalist approach I deem appropriate incorporates particular views about the nature and domain of moral norms-e.g., (1) that certain purported decision-standards do not qualify as "moral norms" (i.e., that a decision-standard must have certain attributes or cannot have other attributes if it is to qualify as a moral norm), (2) that a society of moral integrity must have consistent commitments across its various domains of decisionmaking, etc. I want to indicate that, although I have never been convinced by any purely-conceptual argument for the "objective truth" of a particular norm of justice, I do not reject the possibility that some such foundationalist argument could succeed. For an account of the various types of foundationalist approaches that have been used to identify the universally-applicable norm of justice 
reveal that the United States is a rights-based society of moral integrity, I will focus on the protocol one should follow to identify the moral principle or moral-principle combination to which a rights-based society is committed.

I think that two criteria must be used to evaluate the various possible candidates for a given rights-based society’s "basic moral principle” title. The first relevant criterion is how closely the post-dictions and predictions of various "candidates" for the "basic moral principle" title fit the following facts: (A) the prescriptive-moral conduct of the members of the society and their governments, (B) the moral-rights claims that its members, participants, and governments made and did not make, $(\mathrm{C})$ the arguments that were made and not made in support of the claims in question both by the disputants and by those who evaluated their claims, (D) the conclusions that were reached about the claims in question, (E) how close the "cases" in question were perceived to be, and (F) how certain members of the relevant society were about the proper resolution of the claims in question. The second relevant criterion is the extent to which the nonfits associated with each principle-candidate are explicable in terms that reduce the damage the non-fits do to its candidacy-viz., the extent to which the non-fits can be explained by (A) the greater power of the non-fits' beneficiaries, (B) the presence of mechanical transaction costs or other types of costs that made it unattractive for parties to pursue justified claims or attractive for parties to pursue unjustified claims, $(\mathrm{C})$ the fact that the relevant individuals did not adequately consider the arguments they made, the conclusions they reached, or the conduct in which they engaged, (D) conceptual intellectual errors that the relevant actors might very well have committed, and/or (E) other sorts of errors that may have been committed by moral-right holders or obligors or have been or might be committed by deciders of moral-rights disputes or moralrights-related legal-rights disputes. In brief, in my view, the basic moral principle of a rightsbased society is the moral norm that best discounted-fits its members' and governments' relevant conduct, discourse, and perceptions where the non-fits associated with each "candidate" are discounted by their discount-justifying explicability.

and the various types of conventionalist approaches that have been used to determine whether a given society is moral, immoral, or amoral, to determine whether a given society of moral integrity is rights-based or goal-based, and to identify the particular moral norm that a society of moral integrity is committed to instantiating, see Richard S. Markovits, On the Relevance of Economic-Efficiency Conclusions, 29 FLA. ST. L. REV. 1, 50-54 (2001). 
I believe that the application of these criteria to the results of an acceptably-thorough analysis of the prescriptive-moral discourse, perceptions, and conduct of members of our culture would lead to the conclusion that ours is a liberal, rights-based society of moral integrity. More specifically, such an investigation would yield the conclusion that ours is a rights-based culture whose members and government(s) are obligated to show appropriate, equal respect and concern for all moral-rights holders for whom they are or it is responsible. The liberal duty of appropriate, equal concern covers concern both (1) for the "welfare" of other members of the society in the sense in which economists conceptualize "welfare" (see below) but pre-eminently (2) for these creatures' having the opportunity to actualize their potential to become and remain persons of moral integrity by taking their obligations seriously and striving to establish a reflective equilibrium between their personal value-convictions and their conduct. This conclusion reflects the fact that liberalism values lives of moral integrity more highly than anything else. Although the required "empirical investigation" would take into account official acts by government employees, political acts by private members of our culture when performing political roles, and the conduct of various participants in adjudicatory proceedings, it would primarily focus on the prescriptive-moral discourse, perceptions, and conduct of members of our culture outside of governmental fora or electoral processes.

B. The Tort-Related Corrective-Justice-Related Obligations of the Members and Governments of a Liberal, Rights-Based State

This section analyzes the implications of a liberal, rights-based society's generic commitment to showing appropriate, equal respect and concern for all moral-rights holders for whom it is responsible for (1) the tort-related moral obligations and rights of its members and participants and (2) the obligations of its governments to secure the tort-related moral-rightsrelated interests of those for whom it is responsible. I want to reiterate that these issues are not the types of issues with which many legal philosophers who have focused on the law of torts have been concerned. Admittedly, a few philosophical analyses of tort law have tried to analyze the implications of a particular value (say, libertarianism ${ }^{7}$ ) for the content of tort law in a State that is committed to that value (without ever establishing that any particular society is committed

\footnotetext{
$7 \quad$ See Richard Epstein, A Theory of Strict Liability, 2 J. LEG. STUD. 151 (1973).
} 
to the value in question). However, most tort-law-focused philosophical analyses are not "topdown" ${ }^{\prime 8}$ in the sense of starting with the value rather than with the law. In particular, most tortlaw-focused philosophical analyses start with the law and try to devise the "best” philosophical (i.e., most-morally-attractive) account that can be given of our actual tort-law practice. This orientation may well reflect the relevant authors' subscription to the positivist position that legal practice is self-validating and perhaps self-legitimating. Although I agree that a society's legal practice constitutes part of the universe of prescriptive-moral conduct, perceptions, and discourse on which conclusions about a society's moral character and commitments must be based, I believe that legal practice constitutes only a small percentage of the relevant data and that individual elements of and sometimes broad subsets of a society's legal practice may be inconsistent with its moral commitments and, therefore, internally incorrect. In any event, that is why my philosophical analysis of tort law starts with our society's moral commitments (examines the implications for the common law of torts of my conclusion about our society's moral commitments) rather than with our society's tort law (rather than trying to develop the “best” philosophical account of our common-law-of-torts practice).

I also want to emphasize at the outset that-although the suggestions that follow are more than casual ruminations-I recognize that several are contestable and may well be wrong. I am particularly concerned about the third, "self-conception-related" corollary of liberalism, which asserts that liberalism is specially concerned not only with losses that preclude people from leading lives of moral integrity but also with losses that militate against their leading such lives by affecting their self-conceptions in ways that make it less likely that they will take their moral agency and hence their moral lives seriously. More specifically, my concern about this suggestion is less that it may be false but more that the specific types of losses and constraints that undermine our self-respect in the relevant way may vary from society to society and from group to group or individual to individual within a given society and that the resulting "squishiness" of this category of losses may undermine the practicability of the liberal approach to tort law as a whole.

For somewhat different reasons, I am also troubled by the "non-uniqueness” qualification to the basic liberal duty to rescue that I suggest liberalism may warrant. At least in part, I have

\footnotetext{
$8 \quad$ See Coleman, op. cit. supra note 1 at 184.
} 
been led to propose this qualification to render compatible with liberalism some of our legal system's failure to recognize duties to rescue that one would otherwise conclude liberalism would impose. Although I do think that my discussion of this qualification is relevant and worth considering, I cannot say that I find it thoroughly convincing.

In any event, even if in the end you conclude that one or more of what I claim are tortrelated corollaries of liberalism cannot be said to be so, I hope that my discussion of them will make a contribution by stimulating constructive criticism and the articulation of superior alternatives. If the tone of the rest of Part I is confident, the author is not.

\section{(1) The Tort-Related Obligations of the Members of a Liberal, Rights-Based Society}

My tentative view is that the concrete tort-duty implications of the generic liberal duty of appropriate, equal respect and concern is captured by seven corollaries of liberalism or related sets of such corollaries. Before discussing these corollaries, I want to point out a presupposition of the first five that economists will find uncongenial—viz., that, from the relevant, liberal perspective, not all benefits and harms are commensurable. Economists (or perhaps I should say the overwhelming majority of economists who believe that it is always desirable to make the choice that maximizes "welfare" in the sense of maximizing utility, pleasure, satisfaction, or the kind of "well-being" that is connected with such concepts and the minority of economists who admit that at least some members of our society are committed to a coherent value that implies that the desirability of a choice depends in whole or in part on its impact on the distribution of such "welfare") implicitly assume that all effects of any choice are commensurable. More specifically, in their view, all effects of any choice can be measured in units of utility or pleasure. I doubt that the assumption of commensurability would be justified even if all evaluations should focus exclusively on the kind of well-being with which most economists seem to be exclusively concerned. In particular, I doubt that a single metric can be used to measure such varied psychic experiences as pleasure, satisfaction, ecstasy, unease, unhappiness, terror, etc. However, even if all effects of a choice were commensurable from the perspective of any value that focuses exclusively on such well-being, various effects of choices would not be commensurable from the perspective of the liberal norm on which corrective-justice conclusions must be based in our society. 
Thus, as the first corollary of liberalism I will discuss asserts, from a liberal perspective, any pleasure or satisfaction that an actor obtains by inflicting otherwise-unjusticized pain on, degrading, or controlling another does not count the same for a liberal as the other sorts of pleasures that a choice can confer on the actor. And as all the remaining corollaries of liberalism I will delineate manifest, from a liberal perspective, the conventional pleasures that a choice yields are not commensurable with the loss an individual sustains when a private or governmental choice deprives him of the opportunity to lead a life of moral integrity by killing him, depriving him of the neurological prerequisites for acting as a moral agent, or perhaps subjecting him to life-dominating pain or when a private or governmental choice strongly militates against his seizing the opportunity to lead a life of moral integrity by inflicting losses on him that in the circumstances in question cause him to doubt his authorship of his own life and hence to question his moral responsibility for his actions.

Because the point of the preceding paragraph is critical, I want to restate it somewhat differently. Economists who are concerned exclusively with the maximization or distribution of welfare or utility as they understand those concepts value protecting moral-rights holders' lives, neurological prerequisites for leading a life of moral integrity, privacy, and psychological capacity to lead a life of moral integrity to the extent that the relevant protections increase the utility of their direct beneficiaries and any others they affect. Liberalism values the promotion of lives of moral integrity not primarily because the promotion of such lives increases utility but because it values such lives in themselves. Indeed, liberalism considers promoting lives of moral integrity to be a higher-order value than increasing mere utility. In the current context, this conclusion is salient because it implies that the fact that a choice maximizes utility as economists understand this concept cannot justicize it if it deprives people of the opportunity to lead a life of moral integrity or militates against moral-rights holders' seizing this opportunity by undermining their sense of being the authors of their own lives. ${ }^{9}$ The second through seventh corollaries of liberalism I will discuss all reflect this fact.

$9 \quad$ Another corollary of the fact that liberals value the opportunity to lead a life of moral integrity in itself is that liberals would not base their assessment of the value of this opportunity or of the privacy and self-ownership whose protection fosters people's taking their lives morally seriously by the value that the beneficiaries of such protection and opportunities would place on them if they were maximizers and were perfectly informed about the kinds of things that the economist's conception of individual sovereignty implicates. Although my conclusion that 
In any event, I suspect that most economists will reject the various corollaries of liberalism I will delineate because they will reject the incommensurability premises they manifest. If experience is any guide, many economists will attempt to justify their rejection of these corollaries by arguing that the liberal value that supposedly underlies them is incoherent in the sense of having no substantive content. In so doing, they will be repeating their standard mistake of assuming that the fact that the extensions of some concept are contestable or cannot be derived mechanically from its linguistic definition implies that the concept has no denotation.

I hasten to point out, however, that various philosophically-inclined lawyers who have taken an interest in corrective justice and at least some judges share my perception that our society regards at least some of the harms and benefits that wrongdoing can generate to be incommensurate. For example, Hanoch Dagan has noted with approval the fact that the measure of recovery that is available in "unjust enrichment" suits—compensation for harm suffered, "fair market value" of the resource taken, or profits realized by the wrongdoer-depends on whether in the society in question the resources taken "are viewed merely as valuable assets that have no direct bearing on the identity of their holder" or are "attached to [their] holder's identity"—i.e., on whether the resources taken are "fungible" or "constitutive." 10

\section{(A) The First, Illicit-Satisfaction Corollary of Liberalism}

The first of the seven corollaries of liberalism that I think are relevant to the analysis of the tort-related corrective-justice-related rights of the members of and participants in a liberal, rights-based State is that such individuals cannot justicize imposing a tort-type loss on someone else by citing the satisfaction or equivalent-dollar gain they obtain from inflicting otherwiseunjusticized pain on the other, from degrading the other, and/or from controlling the other. To the contrary, rather than counting for the justness of the conduct in question, the fact that it yields satisfaction for these sorts of reasons counts against its “moral permissibility” (i.e., in my usage,

ours is a liberal, rights-based society reflects my belief that most members of our culture value leading a life of moral integrity in the way that liberalism does, the fact that some members of our society do not would not affect the liberal evaluation of choices that alter the opportunities people have to lead such lives and/or the likelihood that they will take advantage of these opportunities (as it would the utilitarian or allocative-efficiency-oriented evaluation of such choices).

$10 \quad$ See Hanoch Dagan, The Distributive Foundation of Corrective Justice, 98 MiCH. L. REV. 138 at 140, 142 , and 155 (1999) and, more generally, HANOCH DAGAN, UNJUST ENRICHMENT (1997). 
counts against its consistency with such a society's moral-rights commitments) —indeed, may actually guarantee its moral impermissibility (say, when these types of satisfaction critically affected the chooser's decision to make the choice in question). This first, tort-related corollary of liberalism is most relevant to such torts as invasions of privacy, assault, battery, false imprisonment, and intentional infliction of emotional distress.

(B) The Second, "Opportunity to Lead a Life of Moral Integrity"-Related Corollary of Liberalism

The second corollary of liberalism that relates to the tort obligations of members of a liberal, rights-based society applies to the assessment of avoidance-move rejections that may deprive their victims of the opportunity to lead lives of moral integrity—say, by killing them, by depriving them of the neurological prerequisites for leading a life of moral integrity, or (perhaps, if this concept is not disqualifyingly "squishy") by causing them to experience pain that dominates their lives sufficiently to prevent them from considering their obligations, devising their personal conception of the good, and striving to lead a life that is consonant with this conception. According to this corollary, a moral agent who is a potential injurer who knows or ought to have known that his choice might impose a life-of-moral-integrity-precluding loss on another extant rights-bearer will be able to justicize his choice if and only if, after doing appropriate research, he concluded that ex ante his choice should not be predicted to disserve the on-balance, weighted-average "having the opportunity to lead a life of moral integrity"-related interests of those for whom he was responsible. ${ }^{11}$

Thus, the second tort-related corollary of liberalism implies that a pharmaceutical manufacturer whose production would put toxins in the air that will cause some to die or to

11 I do not think that a potential injurer can render legitimate a choice that violates this corollary of liberalism by securing his potential victims' consent to the choice in question by paying them for this consent. Liberalism cannot countenance ex ante consent to the type of choice in question (at least if the society has fulfilled its obligation to provide each rights-bearer for whom it is responsible with the material wherewithal for leading a life of moral integrity so that the consent would not serve the consenter's or his beneficiaries' interests in having the opportunity to lead lives of moral integrity by providing them with material prerequisites for leading such lives that they otherwise would have lacked). Nor do I think that the government of a liberal, rights-based State can discharge the obligations it has in relation to this corollary of liberalism by insuring that all victims of its violation receive compensation from the violator who harmed them. Since, from a liberal perspective, this harm is not compensable, this corollary imposes a duty on the government of a liberal, rights-based State to do everything it can do to prevent 
experience chronic pain that disables them from leading a life of moral integrity would be able to justicize his production-decision only if, after doing appropriate research, he reasonably concluded that the weighted-average-expected number of days of lives of moral integrity that his output (or the last units of his output) would give people the opportunity to lead by helping them survive or easing their pain was not smaller than the weighted-average-expected number of days of lives of moral integrity he should expect the pollution it would generate to deprive people of the opportunity to lead by killing moral-rights holders, depriving them of the neurological prerequisites for leading a life of moral integrity, or subjecting them to life-dominating pain..

Five sets of points need to be made about this corollary of liberalism. The first two are equally applicable to the third corollary of liberalism. I am uncertain about two features of the “opportunity to lead a life of moral integrity"-oriented obligation that liberal, rights-based societies are committed to instantiating. Thus, I am uncertain about whether the second and third corollaries should assert that the relevant choosers are obligated to base their avoidance-decision on the prediction they should make of its net impact on (1) the number of days of lives of moral integrity that relevant individuals are prevented from having the opportunity to lead by death, neurological disability, or chronic pain or (2) the number of extant persons who are prevented by death, neurological disability, or pain from leading lives of moral integrity (though, as the preceding paragraph suggests, I am inclined to think that the former metric is the appropriate standard). Somewhat relatedly, I am also uncertain about whether the second and third corollaries of liberalism should deem relevant any tendency of an avoidance-move rejection to affect the number of individuals with the neurological prerequisites to lead lives of moral integrity that are born (though I am inclined to think it should not). ${ }^{12}$

Second, the second corollary of liberalism (and the third) will at least sometimes imply the fault and hence liability of an injurer who would not be deemed "negligent" in the sense in which that concept is operationalized through the variant of the Hand formula that would be

violations of this corollary that would not preclude it from securing weightier rights-based interests by reducing the society's other types of economic output.

12 See John Broome, Cost-Benefit Analysis and Population in Cost-Benefit Analysis: Legal, Economic, and Philosophical Perspectives (Matthew Adler and Eric Posner, eds.) 117 (2002). For some comments on Broome's analysis of this issue, see Richard S. Markovits, Book Review, __ ETHICS __ (2004)_a review of COST-BENEFIT Analysis: legal, Economic, and Philosophical Perspectives (Matthew D. Adler and Eric A. Posner, eds.) (2002). 
appropriate to use to assess the wrongfulness of conduct that might generate mere-utility losses but could not generate life-of-moral-integrity-related losses in ways other than by reducing the victims' material resources below the level they must have to be in a position to take the moral dimension of their lives seriously. In part, this conclusion reflects the fact that the calculation on which the second corollary bases its fault conclusion ignores the rejection-decision's impact on things other than the number of days of moral integrity that relevant individuals have the opportunity to lead. However, even if this were not the case, the outcome of a Hand calculation might not be the same as the outcome of the second corollary's calculation because (as I have already indicated), unlike the Hand formula, the second corollary does not value the "costs” and "benefits" on which it focuses by the equivalent-dollar value that those who experience these effects place on them (or even by the equivalent-dollar value they would place on them, given their conception of the good, if they were otherwise perfectly informed).

Third, I want to point out that this second corollary can be, has been, and perhaps should be articulated in a way that is consistent with the postulate of liberal dualism, which distinguishes the obligations of the participants in a liberal, rights-based State when acting in their private capacities and the obligations of such a State itself and correlatively of its members when performing political roles. More specifically, the variant of the postulate of liberal dualism that I use in the current context asserts that-because the private conduct of the individual participants in a liberal, rights-based society did not, in general, cause or make them morally responsible for the extant variations in their co-participants' income/wealth positions ${ }^{13}$ or in various attributes of these individuals themselves that affect their abilities to take advantage of any opportunity they have to lead a life of moral integrity - the private duties of the individual participants in a liberal, rights-based society do not (in general) depend on the leading-a-life-ofmoral-integrity-related consequences of their choices that reflect the fact that the income/wealth positions of those the relevant choices affect deviate from the society-average or the fact that those the relevant choices affect have other non-average characteristics that influence their ability to seize an opportunity to lead a life of moral integrity. Hence, although when acting in

13 In a society in which materialism plays a significant role, not only the absolute income/wealth position of an individual but also his relative income/wealth position may affect his ability to take advantage of an opportunity to lead a life of moral integrity by affecting his self-respect.

Articles/09_27_2004_Liberalism_and_Tort_Law 
political capacities, participants in a liberal, rights-based State are morally obligated to ensure that those for whom their society is responsible have the money, more specific kinds of resources, experiences, and opportunities that critically affect their ability to take their lives morally seriously, the private-law duties of such individuals do not in general reflect such considerations-i.e., require only that such individuals do not make choices that disserve the interest of relevant individuals in having the opportunity to lead lives of moral integrity by killing them directly, depriving them of the neurological prerequisites for leading such lives, or subjecting them to life-dominating pain (do not require that potential injurers take account of the possibility that the loss an avoidance-move they have rejected might have prevented would have militated against its victims' taking their lives morally seriously by depriving them of the nutrition, housing, medical care, education, or other experiences that are prerequisites of their making meaningful moral choices).

Fourth, I want to concretize this second postulate and use the examples in question to respond to the objection I mentioned in the Introduction that it would require us to revert to a pre-industrial-revolution economy. I will use three examples for this purpose.

The first focuses on the decision of a pharmaceutical manufacturer to produce additional units of a product that would prolong the life or critically reduce the pain of its consumers in the face of the fact that-even if carefully executed - the production of these drugs would generate pollution that shortened the lives of victims who inhaled or ingested it, would deprive them of the neurological capacity to lead lives of moral integrity, or would subject them to lifedominating pain. The second corollary implies that such a company's production of the relevant units of its product would have been wrongful unless

(1) after doing appropriate research (see the fifth set of corollaries), it reasonably concluded that no alternative method of producing its last units of output or all its output would have been ranked higher under an opportunity-to-lead-a-life-ofmoral-integrity metric (see below);

(2) after doing appropriate research, it reasonably concluded that its last units of production and its overall output would not disserve the on-balance interest of the society's members and participants in having and taking advantage of the opportunity to lead lives of moral integrity because its decision to produce these units would promote that interest more by helping its customers recover from injury or illness, by easing their pain, and/or by inducing others to supply goods or services that increased the opportunity of the society's members and 
participants to lead lives of moral integrity than it would disserve the relevant interests of these individuals by exposing its victims to the toxins it put in the air; and perhaps

(3) although it did not do appropriate research and/or did not properly consider the information at its disposal, those failures did not cause it to make a choice that disserved the relevant on-balance interests of the society's members and participants.

Some explanation is required. As I indicated in the Introduction, an act or activity that does not increase someone's opportunity to lead a life of moral integrity “directly” by prolonging his life, preserving his relevant neurological capacities, or relieving him of life-dominating pain may do so "indirectly" by providing him with needed nutrition, clothing, housing, medical care, or education. Acts or activities can perform this latter function either by supplying such goods and services themselves or by providing goods and services whose availability provides others with the incentive to provide such services. Although relevantly-dangerous choices by pharmaceutical companies may be particularly likely to be rendered non-wrongful by their direct tendency to increase the opportunity that some relevant individuals have to lead a life of moral integrity, the choices of such companies may also generate this type of benefit indirectly by providing others with an incentive to produce needed goods or services.

The second example focuses on the decision of a manufacturer of some product to transport the goods it produces in a way that, in comparison with the situation that would prevail if it did not produce these goods, creates a risk that individuals who are potential victims of vehicular accidents in which its transport vehicles will be involved or of the pollution those vehicles will generate will on those accounts lose the opportunity to lead a life of moral integrity. The second corollary implies that such a company's decision to transport its output in the way in question will be wrongful unless it can demonstrate that, at least as probably as not, one or both of the following two propositions are true:

(1) after doing appropriate research, it reasonably concluded that a switch to any alternative method of transportation that would have served the interest of relevant individuals in having the opportunity to lead a life of moral integrity by reducing the relevant types of accident or pollution losses would not have served those interests on balance because-by increasing the company's marginal costs - it would have induced it to reduce its output in circumstances in which the production, more dangerous transport, and consumption of the eliminated units 
would have promoted the goal of increasing the opportunity relevant individuals have to lead a life of moral integrity on balance or

(2) although it did not do appropriate research and/or failed to process the information at its disposal appropriately, these failures did not cause it to make a choice that disserved the relevant on-balance interest of relevant individuals.

In this more general case, it is less likely that any reduction in the number of units produced would deprive individuals of an opportunity to lead a life of moral integrity directly and therefore more likely that it would have to do so indirectly by reducing the incentives of others to produce needed nutrition, clothing, housing, medical care, and education for the use of the more dangerous method of transport to be non-wrongful.

The third example focuses on a decision by a private actor to take a pleasure-drive in a car that he reasonably believed to be appropriately safe that he would operate appropriately carefully. Since even when driven carefully a car whose driver reasonably and perhaps correctly believed to be safe may be involved in an accident that will deprive someone of the opportunity to lead a life of moral integrity and may generate pollution that has this effect-indeed, may have such consequences for others whose losses cannot be partly attributed to wrongful choices that they made, does this second tort-related corollary of liberalism imply the wrongfulness of such pleasure-drives? Since I recognize that this implication would not fit our societal practice, I would like to be able to provide reasons why this corollary might not deem such pleasure-driving wrongful.

I can think of at least three such reasons. First, virtually all activities create such risks. An enormous number of opportunity-to-lead-a-life-of-moral-integrity-depriving accidents occur around the home. Careful pleasure-driving may not create significantly more dangers of this kind than the other activities people would substitute for it.

Second, the option of taking careful pleasure-drives may motivate some people to supply more or more valuable market labor and the increase in their market product that results may increase the opportunity that others have to lead a life of moral integrity either directly (because the extra goods produced are goods whose supply to them critically affects their opportunity to lead such a life) or indirectly (because the availability of this extra output induces others to produce goods or services whose production increases the extent to which relevant individuals 
have the material, formal-educational, and experiential prerequisites for leading a life of moral integrity). ${ }^{14}$

The third reason why the second tort-related corollary of liberalism may not imply the wrongfulness of pleasure-driving is connected to the third tort-related corollary of liberalism I will delineate. Like this third corollary, it derives from a belief that people will not seize the opportunity to lead a life of moral integrity unless they consider themselves to be morally responsible for their own choices and that private actions and legal rules that strongly limit their options will militate against their doing so by preventing them from concluding that they are the authors of their own lives. In the current context, this concern creates the possibility that any conclusion that pleasure-driving of the type described is wrongful would on balance disserve the goal of promoting lives of moral integrity by deterring people from seizing the opportunity to lead such lives by altering their self-conceptions in a way that makes it less likely that they will take their lives morally seriously.

The fifth and final set of points I want to make about the second tort-related corollary of liberalism concerns its relationship to various other proposals for holding liable injurers whose rejection-choices would not be deemed to violate a Hand-type test that was universally applied to all harm-inflicting choices (including, for example, activity-level choices and choices to enter or stay in business). In particular, various judges and scholars have argued for the internal-to-law correctness and/or (moral) legitimacy ${ }^{15}$ of imposing strict liability on one or more of the

14 The preceding discussions of transport choice focused on the implications of liberalism for the "transportrelated" obligations of commercial concerns and possible pleasure-drivers. The second tort-related corollary of liberalism also has implications for the transport obligations of the governments of a liberal, rights-based State. Unless these governments could not supply the relevant public transport without reducing other expenditures that would promote the opportunity to lead a life of moral integrity to a greater extent, they would be obligated to supply such transport facilities or to induce private parties to do so if such transport would be safer in the relevant respects than purely private transport. Of course, this conclusion would be relevant to the pleasure-driving case only if the pleasure-driver did not value the driving in itself but wanted to drive to get to a location in which he could engage in a desired leisure activity. I should add that I can also imagine circumstances in which the governments of a liberal, rights-based State would be obligated to try to educate their society's members and participants not to have preferences whose satisfaction would create dangers that would be of particular concern to liberals.

15 The textual distinction between the "internal-to-law correctness" and "moral legitimacy" of a legal conclusion assumes that valid legal argument (argument that is supposed to be relevant to the resolution of questions about the substantive content of existing law in the society in question) can generate internally-right answers to at least some extant-legal-rights questions in that society that are morally illegitimate. An answer to a legal-rights question is internal-to-law correct (correct as a matter of law) if it is the unique answer generated by valid legal argument in the society in question. An answer to such a question is (morally) legitimate if it is consistent with the relevant society's moral commitments. As item "(2)" in the list included in the first paragraph of Part 1 indicates, an 
following possibly-partially-overlapping sets of injurers whose avoidance-move rejections were not allocatively inefficient (whose avoidance-choices would not be deemed negligent if an appropriately-revised Hand formula were used to assess their negligence): all injurers who cause any type of harm covered by tort-law; ${ }^{16}$

\begin{abstract}
injurers engaged in an "abnormally dangerous" activity even if (A) the activity were carried out with due care and (B) the chooser's location-choice and activitylevel choice were not allocatively inefficient if its "value" to the "community" was outweighed by the danger it posed; ${ }^{17}$
\end{abstract}

internal-to-law correct legal conclusion may be morally illegitimate if it is based on a textual argument that focuses on a morally-illegitimate provision of the relevant society's constitution. Of course, if this provision is sufficiently important, the relevant society's failure to pass a constitutional amendment that eliminates it will call the society's moral integrity into question.

$16 \quad$ See Epstein, op. cit. supra note 7.

17 This proposal is derived from $\S \S 519-20$ of the RESTATEMENT (SECOND) OF TORTS and (possibly) from the case-law on so-called "ultrahazardous activities" that the RESTATEMENT purports to summarize. More specifically, this proposal amounts to an allocative-efficiency-oriented interpretation of some language in these sections that might be read to imply that the case-law holds activities to be strictly liable as ultrahazardous only if-in addition to meeting the other criteria for this classification — their location and/or intensity is allocatively inefficient—an interpretation under which an activity's location is deemed "inappropriate" if and only if it is allocatively inefficient and an activity's "value to the community" is deemed to be "outweighed by its dangerous attributes" only if the activity altogether or the activity-level that prevailed is allocatively inefficient. If this condition must be fulfilled for an activity to be an ultrahazardous activity and hence subject to strict liability, the doctrine would impose strict liability only on injurers whose choices were negligent in the sense in which economists assume the Hand formula defines negligence (but would not be assessed for negligence under our current practice). The doctrine has clearly been invoked in some cases in which there was no evidence that the injurer had made an allocatively-inefficient activity-level or location choice-e.g., in cases involving fires caused by trucks delivering gasoline to urban gas stations. Before proceeding, I should emphasize that I do not think that this allocative-efficiency-oriented interpretation of these sections of the RESTATEMENT is correct. As the next paragraph of the text suggests, I believe that the key terms in these sections should be interpreted in the way that would make the legal position they articulate identical to my second, life-of-moral-integrity-related liberal postulate.

In any event, two further points should be made about the RESTATEMENT's list of determinants of the ultrahazardous status of an activity. First, the RESTATEMENT lists as separate determinants of ultrahazardousness whether the activity creates a high probability of loss and whether the activity creates a probability of a high loss. The reason why the relevant determinant is not the size of the weighted-average-expected loss is obscure. Second, it is also not clear why the uncommonness of an activity is relevant to its ultrahazardous status or the appropriateness of imposing strict liability on those who engage in it. Perhaps the RESTATEMENT's drafters and ratifiers thought that the likelihood that an activity's victims could engage in most-allocatively-efficient avoidance is inversely related to its uncommonness. If so, I am skeptical of this empirical generalization. For a case in which the uncommonness of the defendant's activity seems to have played a role, see Spano v. Perini Corp., 25 N.Y.2d 11, 250 N.E.2d 31 (1969) (blasting).

One final point may be worth making. The proposal that this note discusses is related to a slightly-different proposal by Landes and Posner that industries be held strictly liable in their infancy but liable only when found negligent in relation to precautions taken when mature. See William Landes and Richard Posner, The Positive Economic Theory of Tort-Law, 15 GA. L. REV. 851 (1981). I have not listed this proposal in the text because Landes and Posner believe that it can be justified by its allocative efficiency (though, admittedly, this claim is different from the claim that it could be justicized as an approach to holding liable injurers who more probably than not were negligent). For an explanation of why this proposal cannot be justified in allocative-efficiency terms and a critique of the contrary argument made by Landes and Posner, see Richard S. Markovits, The Allocative Efficiency of 
(3) injurers who made a choice that (A) caused a kind of loss covered by tort law in a way covered by tort law and (B) unilaterally imposed on another a risk of a substantial loss of a type covered by tort law; ${ }^{18}$

(4) injurers who made a harmful choice that (A) imposed a unilateral risk on its potential victims and (B) imposed an actual tort-law-covered loss of any magnitude on a victim; ${ }^{19}$

(5) injurers who made a harmful choice that (A) imposed a unilateral risk on a victim who (B) could not increase allocative efficiency by avoiding the loss he suffered; ${ }^{20}$ and

(6) injurers who (A) made a choice that imposed a unilateral risk on its victim, (B) had the capacity to foresee that their choice might harm someone else, and (C) had the ability and opportunity to prevent the harm that resulted. ${ }^{21}$

With one possible exception, the second tort-related corollary of liberalism differs from all these proposals in two respects. First, unlike these alternative proposals, it applies only when the loss in question deprives the victim of the opportunity to lead a life of moral integrity in ways other than by reducing his material resources below the level needed to make his formal opportunity to lead a life of moral integrity valuable. ${ }^{22}$ Second, unlike these alternatives, it recognizes that injurers who have imposed the kind of loss on some victims that triggers its

Shifting From a "Negligence" System to a "Strict-Liability" Regime in Our Highly-Pareto-Imperfect Economy: A Partial and Preliminary Third-Best-Allocative-Efficiency Analysis, 73 CHI.-Kent L. REV. 11, 123-32 (1998).

$18 \quad$ See Bolton v. Stone, A.C. 850 (H.L.) (1951).

19 George Fletcher, Fairness and Utility in Tort Theory, 85 HARV. L. REV. 537 (1972).

20 RESTATEMENT (SECOND) OF TORTS $\$ 520$ A contains an example of a falling airplane that seems to be designed to reveal the salience of the victim's inability to engage in allocatively-efficient avoidance.

21 See Stephen Perry Responsibility for Outcomes, Risk, and the Law of Torts in PHILOSOPHY AND THE LAW OF TORTS (Gerald Postema, ed.) 72 (2001).

22 Even those proposals that cover choices that have imposed substantial losses are different from the second tort-related corollary of liberalism in this regard because

(1) many substantial losses do not directly deprive their victims of life or the ability to take their lives morally seriously by diminishing their neurological capacities or subjecting them to dominating pain,

(2) although some substantial reductions in the kind of welfare on which economists tend to focus may so overwhelm the victim as to prevent him from thinking of anything else, most will not,

(3) most substantial reductions in material welfare will not lower any of their victims' positions to a level that requires them to concentrate all their efforts on surviving and securing minimal comfort or deprive them of the education or other types of experiences that may critically affect their opportunity to lead a life of moral integrity, and 


\section{applicability can still exonerate themselves and escape liability by demonstrating that they}

should not have expected their choice to decrease on balance the extent to which the relevant population has the opportunity to lead lives of moral integrity. ${ }^{23}$ The possible exception is the

liberal dualism implies that injurers whose choices have deprived their victims of the opportunity to lead a life of moral integrity by reducing their material welfare below some minimal level are not morally responsible for this outcome.

23 Some comments on the persuasiveness of these strict-liability proposals may be in order. Supporters of the first proposal have claimed that it is required by libertarian values - that just as each individual's self-ownership implies his entitlement (inter alia) to the fruits of his own labor, it implies his obligation to compensate those whom he has harmed. At least two objections to this position are worth noting. First, its proponents have failed to supply either a foundationalist argument establishing the universal, objective truth of libertarian values or a conventionalist argument establishing that our society is committed to libertarian values. Second, as Stephen Perry has pointed out, this libertarian argument does not respond satisfactorily to the reality that tort losses are "scientifically caused" by the victim as much as by the injurer. See Stephen Perry, The Impossibility of a General Strict Liability, 1 CANADIAN J. OF LAW AND JUR. 197, 161-66 (1988) and op. cit. supra note 21 at 85-86. More specifically, libertarian theorists have responded to this difficulty either by developing a non-standard theory of causation that manifests various normative assumptions that are at least contestable and are not in any event particularly linked to libertarian values. Those assumptions include a distinction between acting in the world and passivity whose meaning and moral significance are problematic.

At least if its key terms are interpreted in an allocative-efficiency-oriented way, I also do not grasp how one can justify from a corrective-justice-related perspective the variant of the RESTATEMENT's ultrahazardous-activity provision that would make those engaged in such activities strictly liable even though their location-choices and activity-level choices were not more likely than not to have been negligent. Admittedly, the second and third tortrelated corollaries of liberalism I articulate do imply that participants in an allocatively-efficient ultrahazardous activity that is being carried out with due care have an obligation to compensate victims for certain types of losses they imposed on them even though (1) the injurers did not want to cause such losses and (2) the losses in question were not the "result" of their choice (in the sense of being an effect entailed by a given description of their choice) but a consequence of their choice. (I have borrowed this distinction from Perry, op. cit. supra note 21 at 72-73.) However, the second and third corollaries do not imply that participants in ultrahazardous activities are morally obligated to compensate their victims for any type of loss they imposed on them and do imply that injurers who are not engaged in ultrahazardous activities (whose activities are common or do not create a high probability of a substantial loss) are obligated to compensate their victims for certain types of losses they imposed on them.

I also do not understand the corrective-justice force of the third proposal in the list the text presents. Neither the substantial size of the loss nor the fact that the injurer imposed a unilateral risk on his victim seems morally salient to me. Both the second corollary of liberalism and the third imply that the character of the loss in question is more relevant than its victim-valuated equivalent-dollar magnitude to its sufferer's right of redress. Moreover, both practice and principle call into question the moral relevance of the reciprocal character of the risk to which the injurer and victims have exposed each other. In particular, for two reasons, I do not think that the moral entitlements of victims are extinguished by the fact that they have imposed reciprocal risks on their injurers. First, although the factual predicate of the reciprocal-risk argument may be realistic in some cases-e.g., in vehiclevehicle accidents, it is almost certainly not realistic in the pharmaceutical case or in vehicle-pedestrian accidents. Second, even if the two drivers involved in a single-victim, vehicle-vehicle accident in which no-one was negligent in the standard Hand sense would be deemed equally at fault if fault were assessed by applying some opportunity-tolead-a-life-of-moral-integrity-oriented metric because each imposed the same risk of loss on the other and all other relevant considerations were also equal, this fact would not justify the conclusion that the victim should bear all of the resulting loss. Both in principle and in our legal practice, the fact that $\mathrm{Y}$ has behaved wrongfully by creating a risk that $\mathrm{X}$ may suffer a loss does not relieve $\mathrm{X}$ of the responsibility to compensate $\mathrm{Y}$ for a loss $\mathrm{X}$ wrongfully imposed on $\mathrm{Y}$-regardless of whether the risk that $\mathrm{Y}$ imposed on $\mathrm{X}$ ever materialized. Admittedly, in many reciprocal-risk-creation situations, the victim of the actual loss ( $\mathrm{Y}$ in the above example) will not only have wrongfully created a risk that his injurer $\mathrm{X}$ will suffer a loss but will also have committed wrongful acts that

Articles/09_27_2004_Liberalism_and_Tort_Law 
position of the common law (as represented by $\S \S 519-20$ of the RESTATEMENT [SECOND] OF TORTS) on "abnormally dangerous" activities that are not relieved from liability by their "value" to the "community" - at least if in legal practice (1) activities are treated as "abnormally dangerous" if they create a risk that an extant person (someone who has the requisite potential to lead a life of moral integrity) will be precluded from leading a life of moral integrity and (2) the "value" of an activity to the "community" is defined in this context to depend solely on the activity's contribution to the number of days of lives of moral integrity that relevant individuals have an opportunity to lead-i.e., if in legal practice activities are deemed to be "strictly liable" because ultrahazardous if and only if on balance they disserve the interest of those for whom the community is responsible in being in a position to lead a life of moral integrity.

\section{(C) The Third, "Self-Conception-Related” Corollary of Liberalism}

The third corollary of liberalism that is relevant to the tort obligations of the members of a liberal, rights-based society is that conduct (say, an invasion of the privacy of a loved one motivated exclusively by a desire to learn more about the person loved) may be tortious because it injures self-conception-related interests of the victim on which liberals place an especially-high value even if the injurer does not obtain illicit satisfaction from the acts in question (e.g., from

contributed to the risk of his suffering a loss himself. However, as our legal practice (comparative negligence) increasingly reflects, the proper way to respond to situations in which the victim's loss has been caused by his own as well as his injurer's wrongful conduct is not to bar the victim's recovery but to reduce it by the percentage that his fault constituted of the combined fault of the victim and injurer. For a discussion of various related issues, see Jennifer Arlen, Liability for Physical Injury When Injurers as Well as Victims Suffer Losses, 8 J.L. Econ. \& ORG. 411 (1992) and Re-examining Liability Rules When Injurers as Well as Victims Suffer Losses, 10 INT’L REV. L. \& ECON. 233 (1990).

As my discussion of the fourth tort-related corollary of liberalism I will distinguish should make clear, I also doubt that injurers who have imposed unilateral risks on their victims should be required on that account to compensate them for any type of loss of any size they inflicted on them non-negligently. My skepticism on this issue carries over to the fifth tort-related corollary of liberalism I will delineate, which would impose a compensation-duty on injurers who imposed unilateral risks on victims who could not engage in allocativelyefficient avoidance. Although the contributory negligence of his victim is certainly relevant to the existence or extent of the compensation obligations of someone who would otherwise have a duty to compensate his victims, the fact that an injurer's victim was not contributorily negligent does not establish a basis for holding an injurer liable in the absence of a positive reason for doing so.

Finally, I do not understand why the fact that an injurer has outcome-responsibility for a particular loss (had the ability to foresee and prevent the outcome) that eventuated from a unilateral risk he imposed on his victim justicizes requiring the injurer to compensate his victim for the loss in question. Although I recognize the connection between an individual's having outcome responsibility for some event and that event's being a product of his human agency, I do not see why his outcome-responsibility provides a basis for holding him liable, regardless of whether his victim had imposed a reciprocal risk on him. 
any tendency they have to inflict pain on, degrade, or control the victim) and even if the act in question does not directly preclude its victim from leading a life of moral integrity. More completely, this corollary of liberalism proclaims that an injurer (possibly a government) who has invaded his victim's privacy, significantly harmed his victim’s body, significantly restricted his victim's freedom to choose (given his budget constraint), or taken an unacceptably-high percentage or amount of an individual's earned or unearned income —at least if the "injurer" has done so without obtaining the "loser's" ex ante consent-is obligated to compensate his victim for the attendant loss (regardless of whether this outcome was "a result" of the act in question in the technical sense of being entailed by that action as described or a consequence of the act) unless the choice in question served the ex ante, on-balance, weighted-average interest of the relevant population in having and being able to take advantage of the opportunity to lead a life of moral integrity. As I have already indicated, the basic moral commitment of a liberal, rightsbased society is to individuals' who have the requisite neurological capacity being given the opportunity to lead lives of moral integrity by taking their obligations seriously and engaging in the dialectical process of formulating a conception of the good and leading a life that is consonant with that conception. That is the sense in which liberalism is individualistic ${ }^{24}$ and committed to individual autonomy. This commitment to autonomy - to the fundamental interest that individuals have in choosing and acting on their own conception of the good, constrained only by the identical interest of other members of and participants in their society-carries with it a commitment to protecting each individual's privacy and (within limits) each individual's

24 Contrary to the claims made by many feminist, communitarian, and critical-legal-studies legal scholars, liberalism (or at least the kind of liberalism to which I think our society is committed) does not deny the social embeddedness of human experience and choice or the importance of intimate relationships to human flourishing or to individuals' fulfilling their potential to lead lives of moral integrity. Far from viewing society as consisting of a collection of atomized, separate individuals whose identities are not socially conditioned, the type of liberalism to which I think our culture is committed recognizes that intimate relationships play an important role in individuals' developing self-respect and a conception of the good and provide the context in which individuals can fulfill their obligations and conform their lives to their personal ultimate values. For some examples from the legal literature that contain or report the indicated feminist, communitarian, and critical-legal-studies criticism of liberalism, see Kathryn Abrams, Sex Wars Redux: Agency and Coercion in Feminist Legal Theory, 95 CoL. L. REV. 304,326 (1995); Martha Minow, Part of the Solution, Part of the Problem, 34 U.C.L.A. L. REV. 981, 992-98 (1887); Margaret Radin, Property and Personhood, 34 StAN. L. ReV. 957, 964-65 (1982); Mark Tushnet, Following the Rules Laid Down, 96 HARV. L. ReV. 781, 783 (1983); and RoBERTO UngER, KNOWLEDGE AND Politics 211 (1975). 
"ownership" of his body, freedom of choice, and ownership of the product of his labor and savings.

Liberals are committed to protecting privacy both because doing so reinforces the individual's sense of his self-worth (of his being the type of creature that can make up its own mind about the good) and because-more concretely-privacy protects an individual's anonymity, secrecy, and solitude in ways that promote his ability to lead a life of moral integrity by facilitating his participation in intimate relationships (which often lead to self-discovery and provide a context in which he can fulfill his obligations and actualize his conception of the good), by providing him with the opportunity to contemplate the moral alternatives available to him, and by reducing the social cost to him of experimenting with different life-styles and valuechoices. ${ }^{25}$ Liberals are committed to offering the moral-rights holders for whom they are responsible considerable protection not just for their physical bodies but also for their freedom of choice and the fruits of their labor and saving $\mathrm{s}^{26}$ because the provision of such protection fosters the kind of self-conception that encourages people to take responsibility for the moral quality of their lives.

Obviously, there is no mechanical way to derive the implications of the preceding analysis for the identity of the concrete "self-conception-related interests" that a liberal society is obligated to secure and may choose to secure inter alia by creating a common law of torts that imposes compensation-duties on injurers whose choices have disserved the relevant type of selfconception-related interest or, more generally, “opportunity to lead a life of moral integrity”related interest of the population as a whole. But the contestability of whether a particular loss falls within the category of interest that is specially protected does not imply the vacuousness of this third tort-law-related corollary of liberalism. I believe that this liberal concern that people consider themselves to be the authors of their own lives grounds a good deal of our moral-rightsrelated law—e.g., accounts for the institution of property rights, the Constitutional prohibition of government's taking property except for very special purposes and even then only with just compensation, the fact that (except in very unusual circumstances) a private actor who stands

\footnotetext{
25 I have derived this analysis from Ruth Gavison, Privacy and the Limits of Law, 89 YALE L. J. 421 (1980).

$26 \quad$ I hasten to add that the level of this type of protection that liberalism warrants is significantly lower than the level that libertarians claim is each individual's due.
} 
ready to compensate a property-owner ex post may not seize that party's property even when the resource-transfer in question would increase total utility or allocative efficiency, ${ }^{27}$ and the plethora of no-duty holdings in our common law of torts. ${ }^{28}$

In order to make the examples I used to illustrate the concrete implications of the second tort-related corollary of liberalism appropriate to the analysis of the concrete implications of this third tort-related corollary of liberalism, I would have to change those examples solely by assuming that-rather than creating a risk that one or more individuals would be killed, suffer critical damage to his neurological system, or be subject to life-dominating pain-the choices in question create a risk that one or more individuals would suffer lesser losses whose nonconsensual infliction would disfavor not only the potential and actual victims' taking their lives morally seriously but all members of and participants' in our society doing so by undercutting their belief that they are in control of their own lives, at least if the law does not obligate such injurers to compensate them for these losses ex post.

The basic implications of liberalism for the wrongfulness of choices that create a risk of these lesser kinds of losses are the same as their counterparts for choices that create risks of the more serious kind of loss with which the second tort-related corollary of liberalism was concerned: choosers who created this lesser kind of risk behaved wrongfully unless—after doing appropriate research - they concluded that their choice would not disserve the interest of the relevant population in having an opportunity to lead a life of moral integrity. Moreover, when the conduct in question creates this type of self-conception risk, liberalism may have two further implications, which reflect the fact that liberalism would not condemn individuals' consenting to this kind of risk:

(1) even if it would not be wrongful for an actor to create this lesser kind of risk without obtaining the consent of his potential victims if he could not do so either at all or without generating allocative costs or private costs with behavioral consequences that made the relevant effort counterproductive from the perspective of the "goal" of giving people the opportunity to lead a life of moral

\footnotetext{
27 In my judgment, the reason for this prohibition is not the allocative efficiency of requiring propertytransfers to be effectuated through voluntary market transactions. For a discussion that bears on the exceptional circumstances in which such property seizures are morally permissible, see the analysis on the liberal "duty to rescue” in subsection (F) below.

28 As I will admit when discussing the sixth, duty-to-rescue-related corollary of liberalism, from a liberal perspective, our positive tort law almost certainly errs on the side of finding no duty, though changes in what liberals would regard to be the right direction are clearly taking place.
} 
integrity, it would be wrongful for the actor to impose such a risk nonconsensually when he could promote the above goal by securing his potential victims' consent and

(2) even under conditions in which liberalism would not impose a duty on such a risk-creator to obtain the ex ante consent of his potential victims, liberalism might impose a duty on them to compensate their victims ex post and hence on the government of a liberal, rights-based State to require such risk-creators to compensate their victims ex post.

I hasten to add that both these additional implications are problematic. To see why, note that they imply that it would be wrongful for an actor not to obtain his potential victim's consent to or not to compensate his actual victim for a loss that might be or was generated by the actor's nonwrongful choice when the relevant payment would significantly counter the tendency of the loss to militate against the (potential) loser's taking his life morally seriously by altering his selfconception by making him feel that he is not the author of his own life. For this conclusion to be consistent with my other conclusions about the tort-related implications of liberalism, it must be possible to reconcile it with my conclusions about the duty of members of and participants in a liberal, rights-based society to supply help or rescue-services to others (indeed, to supply them without having a right to compensation for costs incurred), and I do not see how I can effect this reconciliation, given my conclusion that the risk-creator did not act wrongfully in creating the relevant risk (was not morally culpable for his victim's requiring assistance).

One final point should be made about this third tort-related corollary of liberalism. Like its predecessors, it does not imply that the members of and participants in a liberal, rights-based society will be obligated to avoid creating these kinds of risks if and only if they should have perceived their rejection of some related risk-reducing choice to be allocatively inefficient.

(D) The Fourth, Mere-Utility-Related Monetized-Tort-Duty Corollary of Liberalism

This corollary has a limited domain-i.e., applies only in relation to avoidance-choices whose rejection would not preclude its victims from leading lives of moral integrity (see corollary two) and would also not militate against their leading such lives by undermining their conception of themselves as moral agents (the possibility with which the third corollary is concerned). The monetized-tort-duty corollary is that, when acting in non-political capacities and considering avoidance-options whose rejection will not preclude or militate against its 
victims' leading lives of moral integrity in ways other than by reducing the general resources at their disposal, each morally-responsible member of a liberal, rights-based society has a moral duty to make all avoidance-moves that he would conclude would reduce the net certaintyequivalent equivalent-dollar losses he imposed on others (if he did the morally-appropriate amount of research into this issue) that he would find attractive to make if the reduction in such net certainty-equivalent equivalent-dollar losses that the relevant avoidance-move would generate were internalized to him.

This monetized-tort-duty corollary reflects two premises. The first is that the liberal duty of appropriate, equal respect and concern implies that any choice of a moral agent that he realizes or should realize will inflict "net harm" on others without preventing them from leading lives of moral integrity or militating against their leading such lives by undermining their belief that they are the authors of their lives violates his duty of appropriate, equal respect and concern if his decision to make that choice was critically influenced by his placing a lower weight on the "units of harm" he inflicted on others than he would have done had he experienced that harm himself. The second premise-liberal dualism —is relevant to the way in which the relevant "units of harm to others" and "units of benefits to oneself" should be defined. As I have already indicated, the variant of liberal dualism I am employing asserts that, when acting in their nonpolitical capacities, the individual participants in a liberal State do not have a duty to adjust their behavior to take account of variations in the extent to which additional undifferentiated resources would contribute to the mere-utility-type welfare of others or the opportunity of others to lead lives of moral integrity when the putative obligor is not morally responsible for (in the sense of being culpable for) the putative obligee's poverty or other attributes (e.g., physical or mental handicaps, poor education, disposition to take pleasure from material resources, etc.) that affect the contribution that additional resources will make to the putative obligee's mere utility or ability to lead a life of moral integrity. I believe that, in the sense in which I am using this concept, liberal dualism implies that the obligations of individuals who are acting in non-political capacities when making private choices that will tend to affect the certainty-equivalent accidentor-pollution losses others confront depend on those choices' equivalent-dollar effects.

Two additional points are relevant at this juncture. First (roughly speaking), the fourth postulate is consistent with our practice of using a Hand-type formula for negligence to 
determine the culpability of an actor in that this formula does base fault-conclusions on a comparison of monetized costs and benefits. ${ }^{29}$ Second, the fourth, monetized-tort-duty corollary focuses on certainty-equivalent (i.e., risk-cost adjusted) equivalent-dollar gains and losses while its two predecessors focused on weighted-average effects because both mere-utility-related risk costs and life-of-moral-integrity-related risk costs involve the kinds of mere-utility losses that play no role when the opportunity to lead a life of moral integrity is implicated but are relevant when “mere-utility” losses are at stake.

I want to reiterate something to which the Introduction already referred. This explanation of the connection between a cleaned-up version of the Hand formula for negligence and the liberal duty of appropriate, equal respect provides a moral grounding for using the Hand formula to determine an injurer's liability in some types of tort cases-viz., in cases in which his behavior generated "mere utility” losses that he should have anticipated ex ante. I value this fact not only because it improves the fit between our positive tort law and my claim that ours is a liberal, rights-based society but also because the existing alleged normative justifications for the Hand formula are thoroughly unsatisfactory:

(1) allocative efficiency is not a goal in itself and (as we shall see) the Hand formula is not allocatively efficient in any event and

(2) utilitarianism is highly problematic as a moral norm (both because it fails to take relevant differences between individuals seriously and because it may not be possible to measure all experiential effects by a single metric), and there is certainly no reason to believe that the Hand formula will maximize the utility of those creatures whose utility utilitarianism counts. ${ }^{30}$

(E) The Fifth, “Research”-Related Pair of Tort-Related Corollaries of Liberalism

29 Admittedly, to be fully consistent with the variant of liberal dualism I believe is warranted, the Hand formula would have to be adjusted both (1) to reflect the risk-cost consequences of the relevant avoidance-move rejection and (2) to focus on the estimates that the relevant actor should have made of his rejected avoidance-move rejection's allocative rather than private costs and benefits. For an analysis of the difficulty and occasional impossibility of adjusting the Hand formula to take the impact of avoidance-moves on tort-related risk costs into account in a way that would yield a formula whose application would maximize allocative efficiency in an otherwise-Pareto-perfect world, see Richard S. Markovits, Tort-Related Risk Costs and the Hand Formula for Negligence (unpublished manuscript currently under submission and available from the author, 2004).

$30 \quad$ Nor do I think that one can justify making tort decisions depend exclusively on their allocative efficiency by claiming that such a policy would be part of a broader policy-package that would maximize total utility. See Richard S. Markovits, Why Kaplow and Shavell's “Double-Distortion Argument” Argument Is Wrong, GEO. MASON L. REV. (2004). 
The word "research" is enquoted in the above heading because in this context I am defining “research" expansively not only to refer to "efforts to discover (1) new, safer (i.e., lessaccident-and-pollution-loss-prone) production-techniques, (2) locations whose advantages and disadvantages for the relevant use were not previously known but whose use will be lessaccident-and-pollution-cost-prone, and (3) not-yet-discovered product variants whose production and consumption combined would be less-accident-and-pollution-loss-prone but also to refer to the non-innovative efforts of a potential tort-loss cogenerator to identify (4) the avoidance-moves known to others that are available to him and to ascertain (5) the known private and perhaps allocative cost and benefits they would generate. Not surprisingly, in my judgment, the corollary of liberalism that controls the research obligations of a potential injurer in a liberal, rights-based society depends on the type of loss his research might put him in a position to avoid by using any new discovery it yields or any known information it uncovers for him. If this loss is a mereutility loss (with one qualification that will be discussed below), his "research"-obligation will be governed by the monetized tort-duty the fourth corollary of liberalism articulates-i.e., he will be obligated to do the research that would have been profitable for him to do if the equivalent-dollar benefits the use of any discovery it generates or "known" information it reveals to him would confer on others were internalized to him (if he placed the same weight on the average equivalent-dollar gain the research and its use would confer on others as on the average equivalent-dollar it would cost him). If, on the other hand, the loss that the potential injurer might be able to prevent himself from causing by doing "research" and using the "research output” is the kind of loss that would preclude the victim from leading a life of moral integrity or change his (and perhaps others') self-conception in a way that would militate against the victim's (or each of the relevant others') taking his life morally seriously, the potential injurer will be obligated to do the research he should have known ex ante would prevent the combination of his research and the activity to which it related from reducing the ex ante weighted-average number of days of moral integrity that relevant individuals have the opportunity to live if he and others made appropriate use of the discovery it yielded or information it brought to his attention.

I want to make four points about these tort-related "research" corollaries of liberalism. First, the second "research" corollary reflects my conclusion that potential injurers do not have an obligation to ensure that their activities make any much less the largest possible contribution 
to the number of days of moral integrity that relevant individuals have the opportunity to live. This conclusion reflects my suspicion that its opposite would militate against individuals' seizing the opportunity to lead a life of moral integrity by undermining their belief that they are the authors of their own lives - a suspicion that (as we have seen) underlies the third corollary of liberalism just discussed and will also affect my conclusions about the duty of members of and participants in a liberal, rights-based society to provide rescue-services to each other (the subject of the sixth set of tort-related corollaries of liberalism, which will be discussed below).

Second, even if this moral conclusion were not true, potential injurers whose activities made a net positive contribution to relevant individuals' having the opportunity to live days of moral integrity would not have to research themselves into the red or into bankruptcy: even if the research in question would otherwise increase the opportunity to live days of moral integrity, it would not serve this basic liberal "goal” if it induced the researcher to withdraw from an activity whose net effect on the opportunity to live days of moral integrity was not negative.

Third, neither of the two "research" obligations I have described requires the potential injurer to become perfectly informed-to discover all previously-unknown, "desirable” avoidance-options or to uncover all known avoidance-options and their known consequences. Potential injurers who have fulfilled their "research" obligations will usually still be imperfectly informed about the known avoidance-options that are available to them, about those options' private and allocative costs and benefits, about the identity of the conventional research-projects they could execute, about the private and allocative costs and benefits of those projects, and about their opportunity-to-lead-a-life-of-moral-integrity-related costs and benefits.

The qualifications to which my initial account of the "research" obligations of potential injurers referred relates to this reality. The initial account assumed that the potential injurer would be perfectly informed about not only the private but also the allocative costs and benefits of the various "research" projects he could execute. That assumption is unrealistic. In a world in which perfect information about "research"-options is not costlessly available to potential injurers, their "research" obligations (1) will include an obligation to do appropriate research into the identity and allocative or opportunity-to-lead-a-life-of-moral-integrity-related cost and benefits of the research-projects they could undertake and (2) to execute the research projects that the standard would require them to execute if their perception of the relevant costs and 
benefits of their research-options were accurate. Obviously potential injurers whose choices may generate mere-utility losses who did not recognize the conceptual difference between the relevant allocative figures and their private counterparts or did not know how to estimate the relevant allocative parameters-e.g., to move from private-figure estimates to allocative-figure estimates - will have based their decisions on private cost and benefit estimates. And potential injurers whose choices may reduce the number of days of lives of moral integrity some victims can lead who did not recognize the difference between an opportunity-to-lead-a-life-of-moralintegrity metric and an allocative-efficiency metric, will have based their decisions on private or allocative equivalent-dollar-impact estimates rather than on opportunity-to-lead-a-life-of-moralintegrity-impact estimates.

Fourth, finally, and somewhat relatedly, my discussion of the "research" obligations of participants in a liberal, rights-based State has ignored a serious, infinite-regress problem. In order to determine how much "research" he should do, a potential injurer must think about the allocative or opportunity-to-lead-a-life-of-moral-integrity-related costs and benefits of doing research. The problem is: he might also be obligated to consider how much he should think about the respective costs and benefits of thinking about the respective costs and benefits of doing the research and so on and so forth. My unsatisfactory response to this problem is to cut the Gordian Knot-i.e., to assume that the potential researcher will and should just jump in and think about the relevant options and their relevant costs and benefits.

(F) The Sixth, Duty-to-Rescue-Oriented Corollary of Liberalism

The sixth tort-related corollary of liberalism I distinguish summarizes liberalism's implications for the duty to rescue. I will first discuss what I take to be the basic liberal duty to rescue and then discuss a qualification to that basic duty that may provide a liberal justification for our society's failure to impose a legal duty to rescue in some situations in which one might think that liberalism would impose such a duty. ${ }^{31}$

31 In general, our society—indeed, all societies in the common-law family—imposes legal duties to rescue in far fewer situations than liberalism would require. It should be noted, however, that in recent years, legal duties to provide assistance have been imposed on several additional categories of potential "rescuers"-e.g., on store-owners to non-customer companions of customers on their premises and on landowners to uninvited companions of their 
Two initial points should be made about the basic liberal duty to rescue or provide assistance. First, this basic duty arises only when there is some chance that the potential rescuee will otherwise suffer a loss that would eliminate his opportunity to lead a life of moral integrity (say, by killing him) or possibly that would militate against his seizing his opportunity to lead such a life by undermining his belief that he is the author of his own life-at least when the loss in question will not produce such effects solely by reducing the victim's material resources below the level required to survive or to have a meaningful opportunity to lead a life of moral integrity in the society in question. Second, the basic liberal duty to rescue or provide assistance is an accommodation of two corollaries of liberalism that have already been articulated that have conflicting implications for the duty in question. In the one direction, liberalism's commitment to valuing individuals' having the opportunity to lead a life of moral integrity implies that, ceteris paribus, members of and participants in a liberal, rights-based society have a duty to prevent co-members and co-participants from suffering losses that would preclude them from leading such lives and to prevent preventable losses whose non-prevention manifests a kind of disrespect for the victim that is bad in itself and also bad because it alters the victim's (and perhaps various observers') self-conception in a way that militates against his (their) taking his life (their lives) morally seriously. In the other direction, the liberal commitment to valuing individuals' not only having but also seizing the opportunity to lead a life of moral integrity implies that, ceteris paribus, obligations should not be imposed on individuals that would militate against their taking their own lives morally seriously either by creating a risk that they will be damaged in a way that will preclude them from leading a life of moral integrity or by causing them to feel that their life is not their own-i.e., by militating against their leading a life of moral integrity by undermining their belief in their control over their own lives and derivatively in their moral agency. My tentative conclusion is that, from the perspective of liberalism, the following basic duty to rescue (which I believe resembles the moral duty many members of our society believe we all have) would represent the proper accommodation of these two corollaries of liberalism: members of and participants in liberal, rights-based societies are morally obligated to take those steps they can take to prevent other members of and participants

invitees. See William Powers, Book Review of MARSHALl SHAPO, THE DUTY to ACT: TORT-LAW, PowER, AND PUBLIC POLICY, 57 TEX. L. REV. 523 (!979). 
in the society in question (including those to whom they have made no relevant promise, those with whom they have no relevant status relationship, and those whose need for help they did not culpably create) from suffering a loss that would preclude them from or strongly militate against their living a life of moral integrity that they can take without (1) incurring a significant risk of substantial bodily injury or death or (2) devoting an exorbitant amount of time to the rescue effort.

The second duty-to-rescue-related corollary of liberalism—which I call "the nonuniqueness qualification”-qualifies the basic duty to rescue. According to this qualification, a potential rescuer whom liberalism would otherwise obligate to provide assistance to someone in need will not have this duty if he is not the best-placed potential rescuer or perhaps, even more comprehensively, if one or more other moral agents are in a position to provide assistance that liberalism would obligate one or more such others to provide if the other in question were the only potential rescuer who could prevent a kind of loss whose possible occurrence can trigger a liberal duty to rescue without incurring a significant risk of substantial bodily harm or death and without devoting a prohibitive amount of time to the rescue.

I can offer three far-from-satisfactory justifications for or accounts of this non-uniqueness qualification-i.e., for the conclusion that an actor who is not uniquely-well-placed to supply rescue services that liberalism would otherwise obligate him to supply or is not the only member of the set of potential rescuers who would individually be obligated to attempt the rescue if the relevant set included only him will not have a duty to provide the help in question. The first possible justification is convincing when it applies but does not apply to many of the relevant situations. If an individual who would be obligated to effectuate a rescue if he were the only member of the set of potential rescuers for whom that assertion was true reasonably believed that someone else equally capable of effectuating the rescue would definitely attempt to do so if he did not or, more comprehensively, if he reasonably believed that his attempt to effectuate the rescue would not increase the probability that the rescuee would be saved, he would not be obligated to make the relevant rescue-attempt (he would not be at fault for failing to make that attempt).

The next two "justifications" for the non-uniqueness qualification to the basic liberal duty to rescue are problematic even when they do apply. Both fall into the category that philosophers 
call "practical reasons." The first is that a decision to hold liable each potential rescuer whom liberalism would obligate to attempt a rescue if he were the only potential rescuer may produce inferior outcomes from both a rights-related interest and mere-utility perspective by making it less likely that the potential rescuer who was best-placed to attempt the rescue from a liberal perspective would actually attempt the rescue. Normative/conceptual objections aside, this argument is vulnerable to empirical attack: to objections that focus on the realisticness of its possible implicit assumptions that the potential rescuers will themselves know the identity of the best-placed potential rescuer ex ante and that the courts will be able to identify this best-placed potential rescuer ex post.

The third possible justification for the non-uniqueness qualification of the basic liberal duty to rescue is prudential in a sense that I have argued elsewhere ${ }^{32}$ renders its consideration morally illegitimate-i.e., inconsistent with our society's moral commitments. A decision not to hold liable each non-unique, otherwise-culpable potential rescuer in this type of case may be morally attractive (even if it does not induce the government or any other non-governmental entity to supply equally-desirable or more desirable rescue-attempts) because it reduces the likelihood that the government will impose liability on a particular non-unique, non-performing potential rescuer (rather than on another non-unique, non-performing potential rescuer or on no potential rescuer) for illicit reasons-e.g., because of the political opposition, race, ethnicity, etc. of the potential rescuer who was singled out.

Two related issues remain to be discussed: When, if ever, does liberalism imply that someone who has attempted a rescue he was obligated to attempt has a moral right to be compensated for his efforts, and if liberalism does imply that a rescue-attempter is entitled to compensation, by what standard should his compensation be determined? It seems clear to me that liberalism implies that a potential rescuee who was culpable for his imperilment (partly because of the burden his danger-creating choices imposed on his potential rescuers) is obligated to compensate anyone who reasonably attempted to rescue him for the "full" cost the rescueattempter reasonably incurred to attempt the rescue and collect compensation. Note that I did not say that the potential rescuee had an obligation to pay the rescue-attempter a supra-

32 See Richard S. Markovits, Matters of Principle: Legitimate Legal Argument and CONSTITUTIONAL INTERPRETATION 60-64 (1998). 
compensatory fee or the fee that would be most-allocatively-efficient, ${ }^{33}$ given its impact on the number of individuals who put themselves in a position to make a rescue-attempt, the number of such individuals who attempt given rescues, the nature of the rescue-attempts that are executed, the choices that potential rescuees make to avoid becoming imperiled, and the decisions that potential rescuees make about whether to accept or reject offers of rescue as well as the myriad of Pareto imperfections that cause the private costs and benefits of these interconnected sets of choices to diverge from their allocative counterparts. It also seems clear to me that liberalism implies that the formula for the rescue-attempter's compensation should include (1) the private opportunity cost to him of devoting time to the rescue-attempt, (2) (on some definitions, redundantly) the "unpleasantness” cost of attempting the rescue as opposed to spending time in some experientially-neutral way (in some way that was neither enjoyable nor unpleasant), (3) the risk costs he incurred to make the rescue-attempt, given the possibility that he might not be compensated for the full private cost of his efforts, (4) the private transaction costs he reasonably incurred to secure his compensation, and (5) the risk costs he incurred because it was not certain that he would be fully reimbursed for these transaction costs. I am uncertain whether liberalism implies that a potential rescuer's award should be reduced by the intrinsic equivalent-dollar value to him of having attempted and perhaps succeeded in effectuating the rescue.

I am also not sure about the implications of liberalism for the compensation duties of a potential rescuee who became imperiled through no fault of his own. I am inclined to say that such a potential rescuee is not obligated to compensate his rescue-attempter, though as a policy matter this conclusion is disfavored by its tendency to reduce the number of desirable rescueattempts that are actually made as well as the number of people who desirably put themselves in a position to make such desirable rescue-attempts (given the probability that informationimperfections and transaction costs with different origins will preclude the State from securing desirable rescue-attempts and desirable investments in rescue-capacity by threatening to fine or prosecute those who fail to make them or promising to compensate those who do make them).

$33 \quad$ For an exhaustive and exhausting treatment of this issue, see Richard S. Markovits, Marine-Salvage Law: A Third-Best-Economic-Efficiency Analysis (unpublished book manuscript available from the author, 2004). For a somewhat less exhaustive and exhausting treatment of this issue, see Marine-Salvage Law and Marine-Salvage Policy: A Second-Best and Third-Best Allocative-Efficiency Analysis (unpublished Article manuscript under submission available from the author, 2005).

Articles/09_27_2004_Liberalism_and_Tort_Law 
Perhaps the proper response to this problem would be for the State as opposed to the imperiled party to reward people who attempt rescues of imperiled individuals who were innocent of their predicament.

(G) The Seventh, Duty-of-Repair Tort-Related Corollary of Liberalism

The seventh tort-related corollary of liberalism is that individuals who have committed tortious wrongful acts that have harmed a moral-rights holder have (1) a duty to mitigate the harm they have caused-in particular, by making harm-mitigating choices that promote life-ofmoral-integrity-related interests on balance when the harm is life-of-moral-integrity-related and by making choices that are allocatively efficient when the harm is mere-utility-related—and (2) a prima facie duty to compensate their victims fully for the losses they imposed on them. I want to make six points about a tortious wrongdoer's compensation-duty.

First, I believe that a wrongful avoidance-move rejector in a liberal, rights-based society has a duty to compensate his potential accident-or-pollution-loss victims for the risk costs he imposed on them by altering the probability distribution of the uncompensated accident and pollution losses they might incur, regardless of whether the accident or pollution-event in question actually occurs. Second, I believe that a wrongful injurer's duty to compensate his victims extends beyond the conventional loss his wrongful act inflicted on them (and the risk costs the possibility of the loss' occurring and their not being compensated for the loss imposed on them) to include the private transaction costs they reasonably incurred to secure compensation from him (and the risk costs associated with their not being compensated for any reasonable transaction costs they incur to pursue their tort claim). I recognize the contestability of the “reasonableness” of both particular expenses entitled victims incur when pursuing their claim and the overall amount of such expenses they incur. I will not now try to develop a protocol for determining the reasonableness of any given expenditure an entitled tort victim makes to pursue his claim. However, I will say that, if a tortious wrongdoer has a duty to compensate his victim for the transaction costs they incur to obtain compensation from him, the victim has a duty not to abuse the wrongdoer by incurring "unreasonable" dispute-prosecution costs. Third, I think that, when the wrongdoer's tortious act was motivated by his disrespect for the victim-plaintiff in particular, the victim should be able to collect damages for the insult the wrongdoer's tortious act 
entailed as well as for any material losses, physical injuries, physical-injury-related pain and suffering, reasonable dispute-prosecuting transaction costs, and loss-and-transaction-cost-related risk costs it caused the victim to incur.

Fourth, in a liberal, rights-based society, the victim of a tortious act may well have a moral right that enough costs be inflicted on his wrongdoer to prevent the wrongdoer from profiting from his wrong. Although I realize that most corrective-justice discussions do not address this possible “corrective-justice” interest of a wronged party, I can see at least four grounds for concluding that a wronged victim has such an interest. First, the wronged victim might have a property interest that was violated by the tort (say, trespass) and be entitled to the profits the wrongdoer realized from his wrong (to the disgorgement of profits) on this account. Second, the wronged victim might have a legitimate interest in the wrongdoer's not profiting from the wrongful act that was wrongful because it manifested the injurer's particular disrespect for his potential victim. Third, the wronged victim might have a legitimate, retributive interest in the wrongdoer's being punished (though this interest would favor the imposition of enough sanctions on the wrongdoer to make his wrongful act ex post unprofitable as opposed to ex post break-even). And fourth, a wronged victim who was not singled out for disrespect by his injurer might have an entitlement in common with all other members of and participants in his liberal, rights-based society that no one profit by behaving disrespectfully. I should add that, in this last case, the particular victim would not have a right that the wrongdoer be required to pay his direct victim enough damages to deprive him of his profits: if a liberal State has a duty to prevent wrongdoers from profiting from their wrongs in these cases, it can discharge that duty by requiring wrongdoers to pay civil or criminal fines or to put in jail-time in addition to compensating their victims when such compensation would not eliminate the profits their wrongdoing yielded. ${ }^{34}$ Not only would such alternative methods of preventing wrongdoers from

$34 \quad$ I am therefore partially disagreeing with Ernest Weinrib’s “correlativity thesis.” On the one hand, I agree with Weinrib that a tortious wrongdoer's liability to his traditional victims is limited to the loss he imposed on them (at least if that loss is defined to include the risk costs, reasonable transaction costs, and insult costs the wrong imposed on them or caused them to incur) even when the wrong would remain profitable after these losses were repaired. On the other, I believe that a liberal, rights-based State may have a duty to supplement such compensatory damage-awards with enough civil fines and criminal penalties to render the tortious wrongdoer's wrongdoing unprofitable. See Ernest Weinrib, Restitutionary Damages as Corrective Justice, 1 THEORETICAL INQUIRIES IN LAW 1 (1999). Admittedly, as I have already indicated, at least when the wrongdoer's wrong was not motivated (in whole or in part) by his particular disrespect for his actual victim(s), those victims would not have a special 
profiting from their wrongs prevent their victims from obtaining windfall gains, they would also tend to increase allocative efficiency

(1) by eliminating the incentive supra-compensatory damages would give potential victims to decrease allocative efficiency by putting themselves in harm's way by rejecting avoidance-moves whose rejection is either not assessed for contributory negligence or would sometimes mistakenly be found not to be contributorily negligent and

(2) by providing revenue to the government and thereby obviating its raising the funds in question in alternative ways that would decrease allocative efficiency.

The positive law on these issues is complicated. Punitive damages seem to be discretionary and are not available in all cases in which the wrongdoer would profit from his wrong if required to do no more than compensate his victims fully for their loss. Instead, punitive damages tend to be deemed appropriate when the injurer has behaved in a way that is worse than merely negligent-has been grossly negligent, has intentionally committed a wrongful act, or has actively desired to inflict the loss he generated on the actual victim or on someone. When the tort has violated a property right of its victim, the victim is held to be entitled to choose between a tort action in which he would be entitled to damages and an action in restitution in which he would be entitled to recover the "profits" the wrong generated for the wrongdoer (to disgorgement). The word "profits" is enquoted in the previous sentence because it is sometimes measured by the savings the wrongdoer secured by not paying the victim for the right to use his property or paying someone else for equivalent property and is sometimes measured by a higher sum equal to the profits the wrongdoer achieved by using the victim's property rather than doing without it or any equivalent to it. In practice, courts tend to award the higher sum when the wrongdoer behaved more wrongfully (e.g., committed the wrong intentionally rather than carelessly).

The fit between the positive law and the various possible bases for concluding that victims have a right that their wrongful injurers not profit their wrongs is also difficult to assess. The fact that property-right holders are entitled to prevent their injurers from profiting from their

entitlement to the State's fulfilling this duty. Although it seems to me that wrongdoers have a moral duty to surrender the profits they earned from wrongdoing to the State, they clearly would not have such a duty if their making the relevant admission or payment might make them vulnerable to criminal prosecution.

Articles/09_27_2004_Liberalism_and_Tort_Law 
wrongs and to require wrongful injurers who have behaved really badly to pay them an amount that would make the wrong ex post unprofitable, legal-transaction-cost consequences aside, is consistent with the property-based account of this victim right (and with the liberal [and libertarian] accounts of the importance of property rights). The fact that no legal right to punitive damages or profit-disgorgement is recognized in cases of ordinary negligence when the invalid interest is not a property interest may in part reflect an assessment of the insultingness of ordinary negligence and in part a recognition that luck plays a substantial role in determining whether a given negligent choice causes a loss as well as the magnitude of a loss it generates. ${ }^{35}$

Fifth, I want to raise the possibility that-in a liberal, rights-based society-a tortious wrongdoer's moral duty to compensate his victims may be somewhat pro-active (may extend beyond a duty to respond appropriately to justified demands for compensation from his wronged victims to include a duty to incur a reasonable amount of expenses to identify and compensate his victims). Sixth, I want to point out that, although a tortious wrongdoer's duty to compensate his victims is diminished or extinguished by his victim's securing partial or total compensation from another source other than the wrongdoer's own insurance-company (say, the victim's private tort-loss insurer or the government), such cross-payments do not extinguish but merely transfer the wrongdoer's duty to pay from a duty to pay his victims to a duty to pay his victim's payor.

(2) The Tort-Related Obligations of a Liberal, Rights-Based State

(A) The General Tort-Related Obligations of the Governments of a Liberal, Rights-Based State

A rights-based State of moral integrity has a general duty to maximize the extent to which the rights-related interests of those for whom it is responsible are secured and has a related prima facie duty to minimize the damage to rights-related interests that is done by tortious acts. This duty is prima facie because it does not require a liberal, rights-based State to secure this result when doing so would necessitate its sacrificing weightier rights-related interests. I do not

35 Some canonical cases in this area are Beck v. Northern Natural Gas Co., 170 F.3d 1018 (10th Cir. 1999) and Olwell v. Nye \& Nissen Co., 173 P.2d 652 (Wash. 1946). See also Maier Brewing Co. v. Fleishmann Distilling Corp., 309 F.2d 117 (9th Cir. 1968); John P. Dawson, Restitution Without Enrichment, 61 B.U. L. REV. 513 (1981); and GeOrGe E. PALMER, LAW OF RESTITUTION §2.12 at 158, 164-66 (1978). 
think that this last qualification is empirically important in the case of the contemporary United States, but I can imagine situations in which general social poverty put a government of a liberal, rights-based State in a position in which it could not protect the tort-related moral interests of its subjects without generating allocative transaction costs and productivity disincentives that would prevent it from providing its subjects with a sufficient amount of the money, specific goods and services, and specific opportunities that would significantly contribute to their having the opportunity to lead lives of moral integrity for the effort to protect tort-rights to reduce the protection given to moral-rights-related interests on balance.

A society's government can fulfill its duty to minimize the damage that wrongful acts (and in some causation-situations acts that may not be wrongful ${ }^{36}$ ) do to the tort-related moralrights-related interests of those for whom it is responsible in a wide variety of ways: by educating its subjects to render them more likely to fulfill their liberal duty of appropriate, equal respect and concern when considering possibly-tortious choices, by imposing civil fines or criminal penalties on tortious wrongdoers, and/or by giving tort victims a legal entitlement to obtain compensation from their wrongful injurers and enabling them to take advantage of this entitlement (by giving them easy and inexpensive access to justice, by supplying them directly with the information they require to win their cases, and/or by offering rewards to non-victim informants who provide relevant information), etc. Whether liberal, rights-based States have a moral duty to make wrongful injurers pay enough damages, civil fines, and criminal penalties (including jail-time) to prevent them from profiting from their wrongdoing depends in part on whether such a policy is an essential part of any morally-requisite tort-deterrence scheme and in

$36 \quad$ I have in mind step-function damage situations in which a set of avoidance-move rejections none of which is wrongful collectively reduce allocative efficiency or disserve the interest of relevant individuals in having an opportunity to lead a life of moral integrity. Assume a case in which the relevant loss is a "mere utility" loss, that no such loss will be generated if 0 to 49.99 units of pollution are put into the atmosphere, that $\$ 100$ in pollution losses will be generated if 50 to 99.99 units of pollution are put into the atmosphere, and that in the original situation, 30 polluters know that each is putting 2 units of pollution into the atmosphere that he could have avoided emitting at a cost of $\$ 2$. In this situation, allocative efficiency could be increased by $\$ 88$ if six of the thirty polluters avoided though no individual polluter originally made an allocatively-inefficient and hence wrongful choice: at least if as seems probable, no individual could induce others to follow his example, each would assume that his avoidance would cost him \$2 and effect no change in the pollution loss generated. My inclination is to conclude that, in this situation, unless the government would have to generate at least $\$ 88$ in allocative transaction costs and other types of public-finance-related allocative "costs" to induce six of the polluters to avoid completely (or enough polluters to avoid to a lesser extent to reduce the number of units of pollution from 60 to 49.99 or fewer), it would be obligated to do so. 
part on whether one concludes that actual tort victims (or the members of the society in general) have a moral right that tortfeasors be prevented from profiting from their tortious wrongs. As already indicated, if a liberal, rights-based State has a duty to prevent wrongdoers from profiting from their wrongs, that duty does not imply that any wrongdoer's victims are morally entitled to have him pay them sufficient damages to render his wrongdoing unprofitable.

A summary may be useful. I have just argued that the government(s) of liberal, rightsbased societies have important tort-related duties. However, at least if I am correct in concluding that the members of such a society do not have a moral right to receive compensation from their wrongdoer if the government insures them against tort-losses, such a society is not obligated to create a corrective-justice-oriented law of torts, either legislatively or by creating common-law courts and authorizing their judges to make binary decisions that secure the relevant correctivejustice-related interests of the parties before them and the rights-related interests of various others affected by the relevant legal outcomes. However, one way that liberal, rights-based States can discharge part of their tort-related duties is to create and operate such common-law courts.

(B) The Obligations of Adjudicators of Common-Law Tort Disputes in a Liberal, RightsBased State

Part 2 will be concerned with the moral legitimacy of judges' resolving common-law tort cases in the way that is allocatively efficient when this resolution cannot be justified in corrective-justice terms. To prepare the way for this discussion, I want to explain why it is morally impermissible in a liberal, rights-based State (i.e., inconsistent with such a State's moralrights commitments) for judges to make decisions in common-law cases that cannot be justified in liberal-corrective-justice terms. Four points are salient. First, the fact that the cases in question are common-law cases implies that their internally-right resolution cannot be derived from (1) legislation passed by official State legislative decisionmakers or (2) constitutional texts that do something other than articulate the moral rights of those for whom the relevant State is responsible and the moral duties that the relevant State has in relation to those rights. Second, the preceding point implies that any attempt by a common-law judge to resolve a common-law (tort) case in other than corrective-justice terms would amount to an exercise of legislative power by that judge. Third, since the resolution of a common-law case in favor of a plaintiff that is not 
based on the plaintiff's pre-existing corrective-justice rights imposes a legal duty on the defendant that he did not have at the time he rejected the choice the court says he is legally obligated to have made, it seems accurate to conclude that defendants in such cases have been subjected to ex post facto legislation. Fourth, ex post facto legislation violates the liberal duty of appropriate, equal respect and concern for at least four somewhat-overlapping reasons:

(1) because ex post facto legislation is unauthorized, it fails to show the respect that is due to members of the society in question by denying them the ability to be the authors of the laws that constrain them;

(2) it denies its victims political procedural-fairness - i.e., various opportunities they would have to protect themselves in the normal legislative process ${ }^{37}$;

(3) it fails to show the society's members appropriate respect and concern by denying its victims fair notice; and

(4) it fails to show the society's members appropriate, equal respect and concern by facilitating the government's punishing its political opponents and disadvantaging the targets of the prejudices of government officials and/or their constituents (by reducing the extent to which the government is inhibited from imposing losses on particular individuals by the facts that legislative decisions have more widespread applicability and are more difficult to reverse than judicial decisions).

Fifth, if I am correct that the moral principles on which a rights-based State is committed to grounding its moral-rights discourse and conduct are inside its common law, judges who resolve common-law cases by reference to those principles (and the corrective-justice notions they entail) will be finding the law and not promulgating new legislation (even when their conclusions are novel and their reasoning innovative in that they reflect insights into the concrete implications of our society's moral commitments and/or refinements in the conceptualization of those commitments that no other judge, legal scholar, or legal or philosophical commentator respectively had or made), those who are disadvantaged by correct common-law decisions will

$37 \quad$ I admit that this objection may be unjustified for both conceptual and empirical reasons. The conceptual problem relates to the difficulty of providing a coherent or persuasive concretization of the political-participation or political-outcome rights of the members of a liberal, rights-based State (beyond the right of such individuals to have the State act to protect the non-political-rights rights-related interests of those for whom it is responsible). For a discussion of this difficulty, see Daniel S. Markovits, Democratic Disobedience, _ _ YALE L.J. _ _ (2005) (forthcoming). For the possibility that the relevant concern is unjustified for empirical reasons (that the access and influence imperfections that would be connected with such judicial legislation would offset the access and influence 
not be victims of ex post facto legislation, both sides of a common-law dispute will have fair notice of the terms on which it will be decided (since members of and participants in a rightsbases society are responsible for knowing both the abstract moral principles to which membership or participation in that society commits them and the concrete corollaries of those principles), and the probability that government will use the common-law courts to punish its opponents and disadvantage the targets of its prejudice will be reduced (though, given the contestability of the correct answer to many corrective-justice questions, the opportunity for corruption will not be eliminated).

2. The Possible Allocative (Economic) Inefficiency of the Internally-Correct Resolution of Corrective-Justice Claims in Common-Law Tort-Suits in a Liberal, Rights-Based Society

Part 2 delineates and explores twelve reasons why the resolution of either common-law tort-issues or common-law tort-cases that is correct as a matter of law in a liberal, rights-based State may not be allocatively efficient even if no allocative-efficiency problems are caused by (1) any tort doctrine not required by our liberal commitments that is not first-best-allocativelyefficient (allocatively efficient in an otherwise-Pareto-perfect world), (2) the transaction costs that are generated by the making, defending, and processing of tort claims, or (3) any mistake of the relevant tort cogenerators or adjudicative decisionmakers other than those this section discusses.

A. The Fact That the Members of and Participants in a Liberal, Rights-Based Society Have No Duty to Make the Choices that Maximize Their Equivalent-Dollar Gains When Those Choices Are Not Require by the Rights of Others or the Actor's Duty to Take His Life Morally Seriously

Liberalism's implications for the duties that the members of and participants in a liberal, rights-based society are complicated and contestable. This section is based on the following tentative conclusions:

(1) the members of and participants in a liberal, rights-based society do have a duty to take their lives morally seriously — to lead a life of moral integrity;

imperfections associated with legislative-branch and executive-branch legislation), see LAWRENCE G. SAGER, JUSTICE IN PlAinCLOTHES 202-07 (2004). 
(2) this duty grounds the duty of the governments of a liberal, rights-based State to put these individuals in a position to lead such a life by ensuring that they have the health care, police protection, nutrition, housing, clothing, education, experiences, and exposure to alternative value-choices and lifestyles that will contribute significantly to their ability to lead lives of moral integrity and by preventing them from making choices to kill themselves (in most circumstances), to sell themselves into slavery, or (in most circumstances) to become addicted to some drug that will deprive them of a meaningful opportunity to lead a life of moral integrity; ${ }^{38}$

(3) the fact that a liberal, rights-based State's members have a duty to lead a life of moral integrity does not imply that the governments of a liberal, rights-based State have a duty to induce these individuals to lead lives of moral integrity by penalizing their failure to do so since what is valued is individuals' freely choosing to lead lives of moral integrity, though it may imply that the governments of a liberal, rights-based State have a duty to explain the attractiveness of leading lives of moral integrity; and

(4) the individual members of and participants in a liberal, rights-based State have no duty to maximize their equivalent-dollar interests when their failure to do so would not violate the rights of others or their own duty to lead a life of moral integrity.

This fourth conclusion has the following corollary: even if potential avoiders' appropriate estimates of the equivalent-dollar costs and benefits that their various avoidance-options would generate were always accurate and even if the accident law of a liberal, rights-based State of perfect moral integrity would always require accident-participants to make all those avoidancemoves that would reduce the certainty-equivalent equivalent-dollar loss they imposed on others that would be allocatively efficient for them to make and only those avoidance-moves in this category that would be allocatively efficient for them to make, the common law of torts of such a State would not legally obligate potential injurers who belonged to the set of potential victims of their own injurious conduct always to make allocatively-efficient avoidance-choices. In particular, given that private actors in a liberal, rights-based State do not have an obligation to maximize their own equivalent-dollar interests when their failure to do so would not violate any other rights or obligations, a liberal, rights-based State would not be morally obligated to impose

38 The governments of liberal, rights-based States might also be obligated to prohibit and prevent prostitution and polygamy if there were sufficiently good reason to believe that participation in these activities or relationships would in practice cause some of the participants to lose their ability to make autonomous choices.

Articles/09_27_2004_Liberalism_and_Tort_Law 
a legal duty on injurer-victims to make an avoidance-move that would increase allocative efficiency when the avoidance-move in question would not on balance decrease the certaintyequivalent equivalent-dollar harm the chooser imposed on others (when the sign of the move's impact on allocative efficiency was critically influenced by the fact that it would reduce the certainty-equivalent equivalent-dollar loss the injurer-victim in question would inflict on himself). This conclusion implies that the common law of torts of a liberal, rights-based State would fail to increase allocative efficiency by imposing a legal duty on relevant actors to make avoidance-moves whose allocative efficiency was critically affected by the equivalent-dollar gains those moves would enter on the potential injurer/victims in question.

B. The Fact That, in Many Circumstances, a Liberal, Rights-Based State's Members and Participants Will Not Be Obligated to Make Ex Ante Allocatively-Efficient Rescue Attempts

My discussion of the duty-to-rescue-oriented corollaries of liberalism argued that, for two or possibly three reasons, the members of and participants in a liberal, rights-based society may not have a duty to execute an ex ante allocatively-efficient rescue-attempt. First, when the potential rescuee will suffer a "mere-utility loss" if he is not rescued and the potential rescuer has no promise-related, status-related, or culpable-causation-related duty to attempt the relevant rescue, the potential rescuer will have no duty to attempt the relevant rescue even if its execution would be ex ante allocatively efficient. Second, even if the potential rescuee may be prevented from leading a life of moral integrity if he is not rescued, the potential rescuer will have no duty to attempt a rescue if the rescue-attempt would subject him to a significant risk of substantial bodily harm or death, regardless of whether he had the option of executing a rescue-attempt that would be ex ante allocatively efficient. Third, and more contestably, even if each individual member of a multi-member set of potential rescuers would be morally obligated to execute an allocatively-efficient rescue-attempt if he were the only person in a position to make such a rescue-attempt, no individual potential rescuer may be obligated to make the ex ante allocativelyefficient rescue-attempt when more than one person way in a position to make such a rescueattempt. If for any of these reasons the members of or participants in a liberal, rights-based society are not morally obligated to make an ex ante allocatively-efficient rescue-attempt, the common law of torts of such a society will not be allocatively efficient in that it will fail to 
impose a legal duty on such parties to make ex ante allocatively-efficient rescue-attempts even if it would be allocatively efficient for it to do so.

C. The Fact That the Value or Moral Significance That Liberals Assign to the Pleasure That Invaders of Privacy, Batterers, Rapists, and False Imprisoners Obtain Because Their Acts Inflict Pain on, Degrade, and Control Their Victims Differs From the Value That Would Be Assigned to Such (Illicit) Pleasures in an Allocative-Efficiency Analysis

The fact that invasions of privacy, batteries, rapes, and false imprisonment give their perpetrators pleasure by inflicting pain on, degrading, and/or controlling their victims may increase their allocative efficiency — in particular, will affect their allocative efficiency by (1) the number of dollars the relevant injurers would have to obtain in an inherently-neutral way to be left as well off as these pleasures left them minus (2) the net external costs (plus the net external benefits) that (I hope) the generation of such pleasures impose on others who disapprove or approve of individuals' obtaining such pleasures. ${ }^{39}$ Such illicit pleasures may therefore either favor or disfavor the allocative efficiency of the acts that generate them. By way of contrast,

39 At least orally, some Law \& Economics scholars contend that the equivalent-dollar gains and losses individuals experience because they approve or disapprove of some act or state of affairs should not be counted in allocative-efficiency analysis. See, e.g., Matthew D. Adler and Eric A. Posner, Implementing Cost-Benefit Analysis When Preferences Are Distorted in Cost-Benefit ANAlysis: Legal, Economic, AND PhilosophicAl Perspectives (Matthew D. Adler And Eric A. Posner, eds.) 269, 276-77 (2002). However, these scholars have no principled argument for this conclusion-i.e., their only justification for it is the supposed difficulty of measuring such equivalent-dollar gains and losses. In fact, in our worse-than-second-best world (in which Pareto imperfections abound and both data and analysis are inevitably costly and data is virtually always imperfect), I am not convinced that it will be less practicable to estimate such moral-value-generated equivalent-dollar gains and losses than to estimate the kinds of equivalent-dollar consequences on which conventional allocative-efficiency analysis focuses or is supposed to focus. I should say that some philosophers have reached a related conclusion that the overall desirability of a choice should not be affected by so-called "external preferences" (preferences for or against other people's gains and losses) for a very different reason—viz., because, in their view, a procedure that counts external preferences is inegalitarian in that it counts more than once the utility of anyone for whose utility there are net external preferences and less than once the utility of anyone for whose utility there are net external dispreferences. I disagree with this latter position (taken, for example, by RONALD DWORKIN in TAKING RIGHTS SERIOUSLY at 234-38 [1977]). To my mind, taking external preferences into account is not counting the utility of the relevant winner twice. The direct winner's utility-gain counts only directly. The fact that it counts indirectly as well when it shows up in someone else's utility function does not involve double-counting any more than would counting the utility someone else obtained because the utility-gain of the direct winner induced the direct winner to change his behavior in ways that benefited the second party in question. Of course, from some value-perspectives, some external preferences and dispreferences (such as an external dispreference based on a prejudice) might not deserve to be given a positive weight (indeed, might even be assigned a negative weight) at the overall-desirability-evaluation stage of the policy-evaluation process (indeed, might [as the text indicates] render the choice in question rightsviolative if it critically affected the chooser's choice). See the immediately-following text and note $40 \mathrm{infra}$. For perceptive discussions of much of the relevant economic and philosophical literature, see Howard Chang, The

Articles/09_27_2004_Liberalism_and_Tort_Law 
such illicit pleasures will never favor the moral permissibility of the acts that yield them from a liberal perspective. Indeed, from a liberal perspective, the fact that the acts in question generate such illicit pleasures may render them morally impermissible-i.e., may count against them more severely than the statement that they would be assigned a negative value would suggest. Indeed, I say "may" only because the fact that an act generates illicit satisfactions may render it morally impermissible only if those satisfactions critically affected its attractiveness to its perpetrator. $^{40}$

Economists are wont to make two arguments against the conclusion that tort decisions that impose costs on actors whose choices give them illicit pleasures (in my terms but not theirs, that correctly enforce liberal norms in illicit-pleasure tort-cases) may be allocatively inefficient. ${ }^{41}$

Possibility of a Fair Paretian, 110 YALE L.J. 251 (2000) and A Liberal Theory of Social Welfare: Fairness, Utility, and the Pareto Principle, 110 YALE L.J. 22 (2000).

40 In our society, people who consider themselves to be "liberal" in the sense in which I am using this term take at least three different positions on the moral significance of the fact that the perpetrator of an act had an illicit motive for committing it. First, some argue that an individual's motivation for committing an act is irrelevant to its permissibility. I think this position is clearly wrong. The liberal duty of appropriate, equal respect and concern seems to me to imply that the fact that an act manifested its perpetrator's disrespect and lack of concern for one or more others is highly relevant to its moral permissibility. Thus, the fact that an executive in a large company chose not to promote a Black employee because he was prejudiced against Blacks strikes me as highly relevant to whether his decision violates the rejected candidate's moral rights (say, in a case in which the Black candidate was equallyqualified but not more qualified than the successful non-Black candidate and could have made no justified moral objection if a random-choice procedure resulted in the white candidate's selection). (A related issue of contemporary interest is whether a crime is made worse if it is motivated by hate.) Second, some individuals who consider themselves to be liberal in my sense argue that the fact that an individual's commission of an act was motivated by its satisfying his illicit desires renders it morally impermissible only if he would not have found it attractive on balance (henceforth "profitable") but for its satisfying some of his illicit desires. Third, some liberals would argue that the basic liberal principle of appropriate, equal respect and concern implies that any act is rendered morally impermissible by its satisfying the actor's illicit desires (A) at all, (B) to a significant extent, or (C) sufficiently to make it "profitable" to him on that account alone even though this consequence was not necessary for its being "profitable” for him. (In the United States, Constitutional Law experts disagree about a related issue-viz., whether an analog of the second or an analog of some variant of the third position just described should be the test for whether the fact that some of those who made a State decision had an illicit motive for doing so renders it unconstitutional. The analog to the second position would be that the unconstitutional motivation [say] of some legislators render a statute they passed unconstitutional only if it was essential to the passage of the legislation in question. The analog to the third test would be that a statute is rendered unconstitutional by the illicit motivation of [some of] the legislators who supported it only if a significant number of the legislative supporters of the legislation were significantly unconstitutionally motivated to support it, only if a significant number though not necessarily a critical number of its supporters would have rejected it but for their unconstitutional motivations, or only if the relevant unconstitutional motivations were a sufficient condition for its passage. My own position on this moralrights issue [and on the Constitutional-law issue discussed in this parenthetical] is the second position delineated above.)

41 Economists are not inclined to make a third argument that favors their conclusion—viz., the argument that such legal decisions encourage such rights-violations not only by increasing the "profitability" of rights-violating conduct to individuals whose preferences make such conduct allocatively efficient by reducing the "law-related 
First, they point out correctly that moral-rights-violating behavior that would be allocatively efficient if it affected no-one else's choices generate allocative costs by making it "profitable" for its perpetrator's potential victims to make allocatively-costly avoidance-moves. Although this consequence is obviously relevant to the actual allocative efficiency of the relevant moralrights-violating conduct and hence to the allocative inefficiency of decisions to make the relevant moral-rights violators civilly liable, there would be no reason to believe that it would always be critical even if this effect of such a decision were not at least somewhat offset by the tendency of decisions to impose civil liability on such violators to increase their incentive to escape detection and hence the allocative costs they generate when attempting to escape detection.

Second, economists argue that decisions to hold moral-rights violators liable in these cases will tend to be allocatively efficient because they will induce the perpetrators to purchase as opposed to taking what they want-i.e., because they will tend to induce the perpetrators to engage in voluntary market transactions. According to this argument, this tendency promotes allocative efficiency because it puts to a market test the perpetrator's claim that the equivalentdollar value to him of "what he took" is higher than the equivalent-dollar cost to his victim of "his taking what he took." Although there is something to this argument, for two reasons, it does not demonstrate the universal, greater allocative efficiency of market transactions or legal rules that encourage them. The first such reason is less interesting and may be less important: the argument ignores the allocative mechanical transaction cost of voluntary market transactions. Even if, allocative transaction costs aside, voluntary market transactions tend to be more allocatively efficient than involuntary transfers, at least in some identifiable sets of cases, the differences in question may be smaller than the allocative-transaction-cost savings the involuntary transfers permit.

The second reason is more interesting and may be critical in those instances in which it is relevant: the allocative-efficiency argument for inducing individuals to purchase what they want in a voluntary market transaction rather than to take it ignores the fact that the acts of purchasing

cost” of engaging in it but also by encouraging people to develop such preferences in the first place (or, perhaps more accurately, by deterring them from combating the development of such preferences) not just by increasing the profitability of satisfying them but by "expressing” a tolerance for them. I suspect that economists' failure to make this argument (indeed, their general reluctance to admit the "expressive" function of law) reflects their tendency to assume that tastes or preferences are exogenous to the system.

Articles/09_27_2004_Liberalism_and_Tort_Law 
and selling some "things" in a voluntary market transaction sometimes change what is “transferred” from both the original possessor's and the later possessor's points of view in ways that affect the equivalent-dollar value the later possessor obtains and the equivalent-dollar cost the original possessor incurs and derivatively affects the allocative efficiency of "the transfer" in question. Thus, one cannot buy friendship, and paid-for sex is not the same thing as rape or voluntary, unpaid-for sex from either participant's perspective. Because a rapist may place a higher equivalent-dollar value on rape than on purchased sex if he views the rape as more controlling of or more degrading to his victims and because a woman may find it more degrading or self-definitionally costly to sell sexual services than to be the (involuntary) victim of a rape, the fact that the highest price that a rapist would have been willing to pay his victim for her sexual services in a voluntary market transaction is lower than the lowest price his victim would have been willing to accept in a voluntary market transaction in exchange for her sexual services is perfectly compatible with the rape's having been allocatively efficient-i.e., with the conclusion that the equivalent-dollar gain the rapist obtained from his act exceeds the equivalentdollar loss it imposed on his victim. If so, a legal rule that prevented rapes in the relevant set of circumstances would generate some allocative inefficiency. Indeed, the legal rule in question would even generate some allocative inefficiency if it induced a sale of the sexual service if the difference between the equivalent-dollar value and cost of the sold service were lower than its counterpart for the rape.

In short, neither of the arguments that economists make against the conclusion that it will sometimes be allocatively inefficient to make privacy-invaders, batterers, rapists, or false imprisoners who take illicit pleasure from their acts civilly or criminally liable carries the day. Hence, in some privacy, battery, rape, and false imprisonment cases, it will be allocatively inefficient for tort law to effectuate liberal corrective-justice norms. 
D. The Fact That the Value or Moral Significance That Liberals Assign to the Loss That Victims of Privacy-Invasions, Batteries, Rapes, and False Imprisonments Sustain Differs From the Value That Would Be Assigned to Those Losses in an Allocative-Efficiency Analysis

This point is exactly parallel to its predecessor. In this case, the critical point is that, even if the allocative-efficiency analysis takes account of the net equivalent-dollar loss the relevant injurious act imposes on non-traditional victims whose value-commitments (presumably) lead them to disvalue the traditional victims' suffering such losses as well as the number of dollars the traditional victims would have to lose in an inherently-neutral way to be left in a position that those victims would regard as equivalent to the position in which the injurious act would leave them, the effect of such losses on allocative efficiency (the negative equivalent-dollar effect of such losses) would not be the same as the liberal "cost" of such losses. As I have already indicated, at least in part, this difference reflects the fact that liberals are not bound by the evaluations that the actual victims and disapproving "observers" give to such losses, and in part it reflects the fact that liberals use a different "currency" to value such losses-value them not in terms of their direct and indirect equivalent-dollar effects but in terms of the disrespect they manifest for the victims in question and usually for all members of the society in question as well as of their direct and indirect effects on both the direct victims' and others' having and taking advantage of the opportunity to lead lives of moral integrity. I should add that this analysis will apply regardless of whether one is focusing on the consequences of the injurious act or the consequences of the State's finding that act wrongful and requiring its perpetrator to compensate its traditional victim(s). 
E. The Reality That Some Accident-Participants Who Have Done Appropriate Research Into the Avoidance-Moves That Are Available to Them and the Net Effect of These Choices on Either Allocative Efficiency or the Opportunities That Their Society's Members and Participants Have to Lead Lives of Moral Integrity May Misestimate Those Options' Consequences in Ways That Lead Them to Reach the Mistaken but SelfJustifying Conclusion That They Are Morally Obligated to Make a Particular AvoidanceMove That Is Available to Them (That Lead Them to Reach the Otherwise-Mistaken Conclusion That, in Effect, They Are Morally Obligated to Execute the Move in Question)

The fourth "reason" why the common law of torts of a liberal, rights-based State of perfect moral integrity would not maximize allocative efficiency is rather complicated. This argument proceeds in three stages. The first establishes that even tort cogenerators who have fulfilled their duty to do research into the identity and relevant consequences of their various available avoidance-options will sometimes misestimate the consequences of making one or more of the avoidance-moves they currently believe they could make in ways that lead them to make the self-justifying mistake of concluding that they are morally obligated to make the move(s) in question. This mistake is self-justifying because, once the chooser has concluded mistakenly that he was morally obligated to make a particular avoidance-move that was available to him, this mistaken conclusion renders his rejection of the move in question wrongful. Admittedly, the avoidance-move the mistaken injurer failed to make would not have been allocatively efficient (in cases in which the relevant possible loss was a mere-utility loss) or would not have increased the on-balance opportunity of relevant individuals to lead lives of moral integrity (in cases in which the relevant possible loss was a loss that could have reduced such opportunities). However, that fact is consistent with the relevant choice's inflicting a mereutility loss on some individuals or depriving some individuals of the opportunity to lead a life of moral integrity-i.e., with the relevant choice's having wrongfully inflicted a recoverable loss on some moral-rights holders. (This conclusion has no counterpart in the situation in which the injurer believed ex ante that he had an avoidance-move option [that he was obligated to make use of] that he did not in fact have since, in such a situation, his wrongful rejection of this nonexistent option could not harm anyone.) Unless the fact that the wrongful rejection of the avoidance-move in question did not generate a net loss of the relevant kind (conferred net benefits of the relevant kind on others [including possibly the injurer]) that were at least as big as the loss it imposed on its victims for some reason extinguishes the victim's rights, the victim 
would be entitled to recover the loss he suffered because his mistaken injurer wrongfully rejected an avoidance-move that was available to him. I can think of no such reason, though the tort-law rule that victims who have suffered a mere pecuniary loss are not entitled to recovery gives me some pause on this account (since the distinguishing feature of at least some pecuniary-loss cases [e.g., cases in which the plaintiff is a restaurant-owner whose place of business is located next to a formerly-pleasant river rendered foul by culpably-caused pollution] is that, from an allocativeefficiency perspective, most of the victim's losses are "offset" by gains to his rivals [other restaurant-owners who make sales to the customers who no longer frequent the riverside establishment]).

The second stage of the relevant argument focuses on the allocative inefficiency of the avoidance-move the potential injurer mistakenly but self-justifyingly believes he was morally obligated to make. When the loss the potential injurer believed he might generate was a mereutility loss and he should have expected ex ante that his act or activity would impose net equivalent-dollar accident-or-pollution losses on others if he did not avoid, his obligation was to make allocatively-efficient avoidance-decisions, and the move he mistakenly concluded he was obligated to make must have been allocatively inefficient. When the loss the potential injurer believed he might generate was an on-balance reduction in the opportunity that relevant individuals had to lead a life of moral integrity, the move he mistakenly but self-justifyingly believed he was morally obligated to make may or may not have been allocatively inefficient, but clearly some of the moves in question will have been allocatively inefficient.

The third stage of the relevant argument explains why it will be allocatively inefficient for the courts to enforce the rights of such victims. The best explanation I can provide is that doing so will be allocative-transaction-costly, will tend to decrease the allocative efficiency of potential-victim avoidance-decisions, and will have an ambiguous effect on the allocative efficiency of potential-injurer avoidance-decisions. Decisions to enforce victims' rights in these cases will probably increase transaction costs by leading victims to bring suits they would not otherwise have brought and by causing the court in question and future courts to investigate the relevant mistake-issue in any such cases that are brought (even though such decisions may also tend to reduce the allocative transaction costs and public-finance-connected non-transaction-cost allocative costs generated by loss-related government-transfer claims that would be prevented by 
tort awards). Moreover, even in our highly-Pareto-imperfect world, a decision to enforce the victim's rights will tend to decrease the allocative efficiency of potential-victim avoidancedecisions by reducing the incentive of victims to make presumptively-allocative-efficient avoidance-decisions whose rejection will not be deemed contributorily negligent either because the move in question is a type of move whose rejection is never assessed for contributory negligence (or negligence) or because impacted information will cause the trier of fact to make a false-negative error on the contributory-negligence issue. Admittedly, such decisions will have an ambiguous effect on the misallocation that potential injurers generate when making avoidance-decisions. In the one direction, to the extent that such a decision will induce potential injurers who mistakenly believed that some avoidance-move available to them was allocatively efficient to make the move in question, it will tend to decrease allocative efficiency on that account. In the other direction, to the extent that such a decision will induce potential injurers to make avoidance-moves they correctly perceived to be ex ante allocatively efficient by establishing that they will be liable for the losses their rejection of these moves generate even if their perception turns out to have been wrong, it will tend to increase allocative-efficiency on this account (particularly in our highly-Pareto-imperfect world in which the relevant imperfections already deflate potential-injurer avoidance-incentives on balance ${ }^{42}$ ). If, as I suspect, these two effects on the allocative efficiency of potential-injurer avoidance-decisions are pretty much a wash, decisions by courts to enforce the rights of victims in these mistake cases will be allocatively inefficient on balance.

F. The Reality That Some Accident-Participants Who Have Correctly Identified the Avoidance-Moves Available to Them and Correctly Estimated Their Net Effect on the Extent to Which the Relevant Society’s Members Take Their Lives Morally Seriously or on Allocative Efficiency May Still Incorrectly Conclude That They Are Morally Obligated to Make a Particular Avoidance-Move Because They Have Made One or More Mathematical Errors

This argument is perfectly analogous to the argument of the preceding subsection.

42 For an explanation, see Richard S. Markovits, The Allocative Efficiency of Shifting From a "Negligence" System to a "Strict-Liability" Regime in Our Highly-Pareto-Imperfect Economy: A Partial and Preliminary ThirdBest-Allocative-Efficiency Analysis, 73 CHI.-KENT L. REV. 20, 38-95 (1998). 
G. The Possibility That Adjudicators in a Liberal, Rights-Based State That Fulfills All Its Moral Obligations at the Time of Decision May Have Made Internally-Incorrect, Allocatively-Inefficient Decisions in the Past That Have Legitimate, Critical Precedential Weight

Even if one assumes (contrary to fact) that, in cases of first impression, the internallycorrect answer to all accident-law issues would be allocatively efficient, the internally-correct answer to some of those legal issues in later cases may be allocatively inefficient if those issues were internally-incorrectly resolved in an allocatively-inefficient way in earlier cases and decisions to correct the earlier errors would wrong parties who reasonably relied on the precedents in question. This conclusion reflects the fact that the moral significance that liberalism attributes to such precedents may be different from the impact of their existence on the allocative efficiency of following them. ${ }^{43}$

H. The Possibility That Pareto Imperfections May Create Situations in Which the Compensatory Damages That Corrective-Justice Requires Will Not Induce the Relevant Actors to Make Allocatively-Efficient Avoidance-Moves

As I have explained elsewhere in great detail, ${ }^{44}$

(1) imperfections in seller and buyer competition, externalities that will not be internalized by the tort-law decision in question, taxes on the margin of income, actor non-sovereignty and non-maximization, and buyer surplus can all distort the private profitability of avoidance-moves both individually and collectively,

(2) potential-avoider non-sovereignty and non-maximization can both individually and collectively cause potential avoiders to make unprofitable decisions to reject profitable avoidance-moves or to make unprofitable avoidance-moves, and as a result

(3) potential avoiders may not make allocatively-efficient avoidance-decisions even if the law will make them compensate their conventional tort-loss co-generators for the losses their allocatively-inefficient avoidance-move rejections impose on them-i.e., there is no reason to believe that the net distortion in the private profitability of avoidance that Pareto imperfections would generate and the errors

$43 \quad$ For a detailed analysis of the factors that affect the appropriate weight for a liberal, rights-based society to give to precedent if it adopts a system in which previous legal decisions may affect the legal rights of parties to legal disputes, see Markovits, op. cit. supra note 33 at 72-74.

$44 \quad$ See Markovits, op. cit. supra note 42 at 46-50 and 74-48 (1998) and Richard S. Markovits, Monopoly and the Allocative Inefficiency of First-Best-Economically-Efficient Tort-law: The Whys and Some Therefores, 46 CASE W. RES. L. REV. 313 (1996). 
that potential avoiders would commit when making their avoidance-decisions would in the relevant sense cancel each other out.

Since adjudicators in common-law tort cases in liberal, rights-based societies are obligated to set damages at a level equal to the loss the victims suffered, ${ }^{45}$ it would be internally incorrect for them to adjust their damage-award in a given case to the level that would be required to induce (say) the injurer to make allocatively-efficient avoidance-decisions. Indeed, even if the damageawards required by liberal corrective justice include compensation for the transaction costs an entitled victim reasonably incurred to pursue his claim and even if potential victims of a culpable non-avoider are entitled to receive compensation for the risk costs their injurer's non-avoidance imposed on them, the internally-correct damage-award in a common-law tort case in a liberal, rights-based society may be allocatively inefficient.

The following two numerical examples illustrate this possibility. The first illustrates the problems that Pareto imperfections beyond the control of the tort-case adjudicator can cause by distorting the profitability of avoidance even if the relevant potential avoider is a sovereign maximizer. Assume the following facts:

(1) the private cost of the rejected allocatively-efficient avoidance move to the injurer was $\$ 105$;

(2) those private costs were undistorted-i.e., the allocative cost of the relevant avoidance-move was also $\$ 105$;

(3) both the potential victims and the potential injurer are indifferent to risk;

(4) the rejected allocatively-efficient avoidance-move would have reduced from $20 \%$ to $10 \%$ the probability of the victim's suffering a $\$ 1,000$ loss-i.e., would have reduced the potential victim's weighted-average-expected loss by $\$ 100$;

(5) the victim would not have had to incur any private transaction costs to collect his claim if his injurer would be found liable, and the processing of any loss-related legal claims (and insurance and government-transfer claims) would generate no allocative transaction costs;

45 I ignore punitive damages, whose award in any event would not be guided by the goal of maximizing allocative efficiency. I should add that I suspect that the award of punitive damages may be illegitimate in commonlaw tort cases in a liberal, rights-based society—at least to the extent that such damages do not constitute compensation for the extra harm the victim suffered because of the particularly-insulting character of the choice that made the injurer liable. This conclusion is compatible with the legitimacy of a liberal State's imposing civil fines or criminal penalties on injurers whose conduct might currently cause them to have to pay punitive damages. 
(6) the $\$ 1,000$ loss the injurer's avoidance-move might have prevented would have consisted solely of lost wages that the avoidance would have prevented by preventing the temporary disablement of the victim in question;

(7) because the potential victim's labor increased the unit output of an imperfect competitor who did not engage in price discrimination and whose valuation of the victim's labor-product was not distorted by any other Pareto imperfection, the allocative benefits that the avoidance would have generated if it prevented the potential victim's disablement (the allocative value of his output if [as I will assume] he was indifferent between working in an uninjured state and consuming leisure while temporarily disabled) would have been $\$ 1200 ; ;^{46}$ and

(8) the potential avoiders (injurers) whose avoidance-choices will be affected by the legal ruling in question will be large, sophisticated companies that either will know or should know that the allocative value of their potential victims' labor will be higher than the victims' wages-more particularly, that the allocative benefits of avoidance will be $\$ 120=(10 \%$ of $\$ 1200)$ rather than $\$ 100=(10 \%$ of $\$ 1,000$ ) — and that the avoidance-move in question will therefore be allocatively efficient.

Now assume that the adjudicator knows all these facts, concludes on this basis that the injurer's avoidance-move rejection was wrongful, and therefore holds the injurer liable. In this type of case, corrective justice would require that the injurer fully compensate the victim for his loss-i.e., pay the victim $\$ 1,000$. But if the injurer did not have to incur any private transaction costs to settle or litigate the victim's claim or to pay these damages (and possibly even if he did), the prospect of these damages' being awarded would not induce him or his future counterparts to make the allocatively-efficient avoidance-move in question since the private cost to him (and them) of rejecting that move (the weighted-average-expected amount of damages the rejection would cause him to pay $-10 \%$ of $\$ 1,000=\$ 100$ ) would be lower than the private cost to him of making the move (\$105).

The second example illustrates the relevance of the potential avoider's non-sovereignty and non-maximization in an otherwise-Pareto-perfect world. This example maintains all the assumptions of its predecessor except that it assumes that the private benefits of avoidance were

$46 \quad$ Roughly speaking, ceteris paribus, the allocative value of the unit output produced by a laborer who works for a non-discriminating imperfect competitor will be higher than the value of his output to his employer (and hence the wage the worker receives) because the allocative value of his output equals the price for which it will be sold while its value to his employer depends on the lower marginal revenue its sale yields him.

Articles/09_27_2004_Liberalism_and_Tort_Law 
not distorted and that the private cost of avoidance was \$95. In this case, the avoidance-move would have increased allocative efficiency by $\$ 5$, the potential injurer in question would be culpable and therefore be found liable for rejecting it, and the avoidance-move in question would therefore be profitable for him to make. But now assume that-despite that fact-the relevant potential injurer would not make the move in question because he would underestimate the relevant private and allocative benefits, overestimate the relevant private and allocative costs, or simply not pay attention. In such a situation, allocative efficiency might be increased by a rule that awarded victims supra-compensatory damages-i.e., the allocative-efficiency gains such a rule would generate by inducing potential injurers to avoid by causing them to pay more attention, to make more accurate estimates of the relevant costs and benefits, or to do their maths correctly might exceed the allocative-efficiency losses the rule might generate by inducing victims to reduce allocative efficiency by putting themselves in harm's way by making allocatively-inefficient choices that will not in practice be found contributorily negligent and by inducing potential injurers who fear that they may be incorrectly found to have been negligent to overavoid from the perspective of allocative efficiency. However, even if this is the case, it would be internally-incorrect for adjudicators in common-law tort cases in a liberal, rights-based State to award entitled tort-victims supra-compensatory damages.

I. The Possibility That No Damage Award a Court Could Make Would Minimize the Amount of Misallocation Caused by the Type of Contingency With Which a Given Tort Case Was Concerned

So far I have assumed that, if the liberal conception of corrective justice required a common-law court in a liberal, rights-based society to award the plaintiff in a common-law tort suit the damages that would minimize tort-contingency-related misallocation, a perfectlyinformed trier-of-fact and court would be able to do so. This section points out that, in many situations, even if the court makes the damage-award that is the most-allocatively-efficient award it could make, its decision would not constitute the most-allocatively-efficient response the State could make to the relevant tort contingency for reasons unrelated to the allocative-transactioncostliness of adjudicative proceedings.

The problem is that 
(1) in general, in order for a public decisionmaker to be able to induce $\mathrm{X}$ types of decisions to be made allocatively efficiently, he must have $\mathrm{X}$ policy-instruments at his disposal and

(2) when the allocatively-efficient response for private actors to make to a tort contingency includes fixed-cost as well as variable-cost decisions, common-law courts will not have enough policy-instruments to induce all the relevant types of decisions to be made in an allocatively-efficient way.

For example, when the allocatively-efficient response to a possible-rescue contingency involves the execution of allocatively-efficient rescue-operation investments as well as the execution of rescue-attempts that are allocatively efficient, given the investments that have been made, the most-allocatively-efficient award that courts could offer a successful rescuer might not minimize the total allocative cost the relevant contingency generates because the award that would eliminate rescue-attempt, rescue-attempt-offer acceptance/rejection, and potential-rescueeavoidance misallocation might cause rescue-operation-investment misallocation and vice versai.e., because the most-allocatively-efficient response to the relevant contingency would require an appropriate set of investment-subsidies to be combined with an appropriate set of damageawards. ${ }^{47}$

I should not close this section without admitting that this possibility may not belong in Part 2's list since it does not suggest a reason why a common law court should not make the most-allocatively-efficient decisions it could make-i.e., because it indicates only that in some circumstances that decision will not be so allocatively efficient as a more complicated policypackage to which it might belong.

I have placed asterisks at the end of the preceding paragraph because the next three reasons why the common law of torts of a liberal, rights-based society may not be allocatively efficient are connected to what I will refer to as our society's binary conception of correctivejustice rights. According to this "binary" conception of corrective-justice rights, in order to demonstrate that he has a corrective-justice right to compensation from someone he alleges has

$47 \quad$ For a detailed theoretical analysis of this kind of possibility, see Richard S. Markovits, Marine-Salvage Law and Marine-Peril-Related Policy: A Second-best and Third-Best Economic-Efficiency Analysis of the Problem, the Law, and the Classic Landes and Posner Study (unpublished article manuscript under submission, 2005).

Articles/09_27_2004_Liberalism_and_Tort_Law 
wrongfully and tortiously harmed him, a victim must establish that more probably than not the defendant made a wrongful choice that violated his duty to the victim and that was a but-for cause of the victim's loss. ${ }^{48}$ This conception of corrective-justice rights is "binary" because, under it, a "defendant" who may have been a wrongful but-for cause of a loss is liable for the full loss if it is found that, more probably than not, he made a wrongful choice that was a but-for cause of the loss' occurrence (regardless of the fact that the probability that he made a wrongful choice that was a but-for cause of the loss was under 100\%) and is liable for none of the loss if the probability of his having been a wrongful but-for cause of the loss was not higher than 50\% (despite the fact that the probability that he had made a wrongful choice that was a but-for cause of the loss was higher than $0 \%$ ).

This conception of corrective-justice-right claims has two critical elements. The first is the "but-for cause" element of moral causation, which I perceive to be an ineliminable feature of any conception of corrective-justice-right claims-i.e., not to be particularly connected to either liberalism or the binary conception of corrective justice. The second element of the binary conception of corrective-justice-right claims is its more-probable-than not element, which is its defining component and determines the loss-division it sanctions in all cases in which the loss has not been but-for caused more probably than not by the wrongful conduct of both the putative injurer and the victim. Although I do not find this defining feature of the binary conception of corrective justice inconsistent with liberal principles of justice, I also do not think that it is entailed by liberalism. Loss-division protocols under which the division of the loss varies more continuously with probabilities of wrongful but-for causation would seem to me to be equally compatible with liberal concerns that possible wrongful injurers be treated in a way that encourages them to consider themselves to be the authors of their own lives and that possiblywronged victims be treated with the respect that is their due.

\footnotetext{
$48 \quad$ I realize that the common law of the United States may not have adopted this rule of liability even in negligence cases - in particular, may require that the victim show only that (1) more probably than not, the defendant caused the loss. To see why this requirement differs from the corrective-justice requirement I have articulated, assume that (1) the probability that the defendant behaved wrongfully is $70 \%$ and (2) the probability that the defendant's wrongful conduct would have caused the loss had eh engaged in it is $50 \%$. On these fact, the defendant would be liable under American law as described even though the probability that he wrongfully caused the loss-(70\%)(60\%) $=42 \%$ - was not higher than $50 \%$ (was not sufficiently high for the plaintiff to have established his corrective-justice claim against the defendant).
} 
In any event, the first two of the next three reasons why the common law of torts of a liberal, rights-based society may not be allocatively efficient relate to the "but-for causation" conception of moral responsibility that I do think is primitively correct and therefore not specially connected to liberalism, and the last of these three reasons is at least somewhat connected to the binary character of our society's conception of corrective-justice rights, which I believe is consistent with though not required by liberal commitments.

J. Simultaneous-Independent-Causation Cases and the "But-For Causation" Element of Corrective-Justice-Right Claims

Assume that (1) the independent choices of two or more actors belonged to two or more different sets of sufficient conditions for the generation of some loss, (2) each such choice would be allocatively inefficient if none of the other choices were made, (3) all such choices combined were allocatively inefficient, (4) the relevant sets of sufficient conditions were fulfilled at times that resulted in two or more such sets' "causing” the loss to occur simultaneously, and (perhaps redundantly) (5) the loss was not increased by the fulfillment of more than one set of the relevant sets of sufficient conditions. In situations of this kind, it would be allocatively efficient to prevent the relevant choices from being made. However, for two reasons, no court may be authorized to resolve a common-law (corrective-justice-based) tort suit in such a situation in the way that would be allocatively efficient. First, in this type of situation, the corrective-justicebased common law of torts may not be able to secure allocative efficiency by holding all the relevant choosers liable because no individual chooser was a but-for cause of the loss that resulted. (I will refer to choosers in this situation as "putative injurers” because no such choosers are "but-for causes" of the loss.)

Second, in at least some of these situations, a common-law court may not be authorized to reach the allocatively-efficient conclusion because none of the putative injurers may have behaved wrongfully. At least, this conclusion is warranted when (1) the individual putative injurers' failures to avoid were independent-when each believed that the others would fail to avoid regardless of what he did, (2) each individual putative injurer knew that one or more others was sufficiently likely not to avoid for his avoidance-move rejection not to be allocatively inefficient or wrongful for a life-of-moral-integrity-related reason, and (3) the profitability or 
attractiveness of not avoiding to each putative injurer was not critically affected by his desire to have the loss generated. ${ }^{49}$

An ingenious argument made by my colleague David Robertson requires me to qualify the preceding two paragraphs. Robertson suggests that, at least when there are just two putative injurers whose choices are members of one or more sets of sufficient causes of a loss whose fulfillment will "cause" that loss simultaneously and neither avoids, each is a wrongful cause of the loss because each has either caused the physical loss wrongfully or tortiously impaired the victim's cause of action against the other. ${ }^{50}$ Robertson is bothered by the fact that the "impairment loss" is a pure economic loss. However, that American-positive-law concern is not germane to my argument: although in some cases there may be sound grounds for holding pure economic losses not to be actionable, doing so cannot be justified in the kind of situation with which this section is concerned. Admittedly, Robertson's argument would have the consequence of causing a second potential avoider to engage in socially pointless, presumably costly avoidance once a first potential avoider had mistakenly failed to avoid. But this possibility would be practically important only if the first potential avoider made a mistake since Robertson's argument would make it profitable for the first potential avoider to avoid—at least if it were conjoined with an appropriate set of damage-assignment rules.

In any event, standard textbook examples of this type of situation include cases in which a house is simultaneously consumed by two or more fires each of which was caused wrongfully,

$49 \quad$ Each such choice would clearly be wrongful if all such choices were interdependent in the sense that none would be made if we were not made since in such a situation each of the relevant choices would be a but-for cause of the loss' occurring. At least, this conclusion would be warranted if, as I suppose, such chooses could not absolve themselves by arguing that they were not responsible for though he caused the choices of other because these choices were made by autonomous choosers.

I also am confident that the individual choices in question are wrongful when each individual chooser believes that his choice will be a but-for cause of the loss-does not know ex ante that the loss would be caused in any case by the satisfaction of one or more other sets of conditions to which his choice does not belong (one or more other sets that may or may not include human choices).

I admit, however, that in this situation the wrongfulness of the relevant choices is more problematic when each individual chooser did not know and should not have known that his choice would affect the outcome-i.e., did the research he was obligated to do and concluded, reasonably that the loss would occur regardless of what he did because Mother Nature either on its own or in combination with choices of others would cause exactly the same loss to occur at exactly the same time. I am inclined to say that some choices made in this situation are wrongful because they manifest the chooser's desire for the loss to be inflicted-i.e., because they manifest the chooser's wrongful disposition. Of course, this characterization will be justified only if the choice in question would not have been attractive to the chooser had he not valued (however non-rationally) its connection to the loss' generation.

Articles/09_27_2004_Liberalism_and_Tort_Law 
cases in which an individual is simultaneously killed by two or more bullets that were wrongfully shot, and cases in which a pollution-loss was simultaneously caused by two or more sets of pollutants that were wrongfully discharged by different polluters in circumstances in which the second through $n$th set of pollutants did not affect the resulting loss. ${ }^{51}$ I suspect that such simultaneous-causation cases occur very rarely, though the importance of possible cases of this kind is undoubtedly enhanced by the inability of relevant victims to prove that, more probably than not, one such set of sufficient causes "first caused" the loss.

K. “Overdetermined" Step-Function-Loss Cases and the "But-For Causation” Element of Corrective-Justice-Right Claims

Assume that the function that relates the loss that will result from varying amounts of pollution's being put into some medium is a "step function"-i.e., would be represented in a two-dimensional diagram in which the loss was measured along the vertical axes and the pollution along the horizontal axis as a series of disconnected horizontal lines that could be connected by verticals at their successive end and beginning points. Environmental specialists indicate that this type of loss function is not uncommon. ${ }^{52}$ Thus, it is said that in the riverpollution context, below some level of pollution, no harm results; suddenly, at a particular level, one cannot swim in or fall into the river without incurring some health risk; over some range above that level, additional pollution does not change the resulting loss; and then suddenly at some higher level of pollution, the fish are no longer edible; again, over some range above this latter level, additional pollution does not change the environmental loss; and then suddenly when pollution increases above some level, the fish die and the river smells. Assume in addition that (1) each of 30 polluters put two units of pollution into some body of water without influencing his fellow polluters' decisions to pollute, (2) no loss would be generated by the presence of zero to 49.99 units of pollution, (3) \$100 in mere-utility losses would be generated by the presence of 50 to 120 units of pollution, and (4) the cost to each polluter of eliminating part or all of his

50 See David W. Robertson, The Common Sense of Cause in Fact, 75 TEx. L. REV. 1765, 1787-89, 1789-99 \& n. 107 (1997).

51 In most such pollution cases, the choices of the individual polluters will not be wrongful for the reason indicated at the end of note 48-viz., because, in most such cases, the decision to pollute would be profitable even for a chooser who did not place a positive value on the pollution-loss that was generated. 
pollution was \$4. Although on these assumptions it would be allocatively efficient for 6 polluters to eliminate their pollution in the situation in question (although their reducing the total amount of pollutants in the water from 60 units to 48 units would increase allocative efficiency by $\$ 100-6[\$ 4]=\$ 76)$, the common law could not secure this result by making the polluters liable to their victims because, for two reasons, no victim would have a corrective-justice claim against any individual polluter: (1) because no polluter was a but-for cause of the loss in question (because no individual polluter's pollution affected the loss either directly or by influencing other polluters' pollution-decisions since each's pollution raised total pollution from 58 to 60 units) and (2) because, on the above account no individual polluter behaved wrongfully by polluting (since each’s pollution was allocatively efficient—saved him \$4 in abatement costs and caused no damage).

L. Imperfections in the Information Available to the Trier-of-Fact on the "More Probable Than Not” Element of the Operative Conception of Corrective-Justice-Right Claims

I have already referred to one kind of causation-information whose imperfect availability can render allocatively inefficient the internally-correct resolution of a common-law tort case in a liberal, rights-based State-information on whether a possible simultaneous-independentcausation case is an actual simultaneous-independent-causation case and, if not, on the identity of the "first causer" of the loss in question. If the trier-of-fact cannot determine that there was a "first causer" and/or the identity of the "first cause," the common-law court will not be authorized to hold any putative injurer liable even if one of them was a "first causer" and it would be allocatively efficient for all of them to avoid. By way of contrast, if the trier-of-fact could determine that there was a "first causer" and could identity not only him but also the “second through $n$th causers," it would be authorized to hold all of them liable if each's failure to avoid were wrongful because each would have been a but-for cause of part of the loss that resulted. In fact, at least if each potential injurer should assume that the others would act as sovereign maximizers if he avoided, the decision of the first potential injurer not to avoid would be wrongful since, regardless of where he is placed in the time-ordering, the loss would not occur

52 See, e.g., Bruce A. Ackerman, Dale W. Henderson, Susan Rose-Ackerman, and James Sawyer, JR., THE UNCERTAIN SEARCH FOR ENVIRONMENTAL QUALITY (1974).

Articles/09_27_2004_Liberalism_and_Tort_Law 
if he avoided and ex hypothesis the prevention of the loss' occurring at any time was allocatively efficient. I should add that in this situation there would also be no loss-division-injustice problem: all the loss would be and should be allocated to the actor whose failure to avoid was a but-for cause of its generation (i.e., to the initial non-avoider).

The second type of causation-information whose imperfect availability can make the resolution of a common-law tort case that is correct as a matter of law allocatively inefficient also relates to the identity of the putative injurer who was the but-for cause of the loss. Assume that in a non-simultaneous-causation case the party who has suffered a loss (1) can demonstrate that two or more actors who had a relevant duty toward them made duty-violating, allocativelyinefficient choices that more probably than not caused some individuals to suffer the kind of loss the victim in question suffered but (2) cannot prove that, more probably than not, any particular injurer had caused his loss. In some cases of this kind (e.g., when the loss was asbestositis that was caused by the inhalation of one unit of asbestos and asbestos was wrongfully put into the air that the victim breathed by two or more polluters, none of whom was more likely than not the source of the asbestos the victim inhaled), at no point in time would it have been possible to identify the particular wrongdoer who harmed the victim. In other cases of this kind (e.g., cases in which the victim's illness was caused by his ingestion several years earlier of a medicine that was wrongfully produced by two or more pharmaceutical companies none of which was more likely than not his ultimate supplier), it would have been possible at an earlier point in time to identify the particular manufacturer-wrongdoer who harmed the victim in question (viz., at the time at which the prescription-filling record was recoverable) but was no longer possible to do so at the time at which the victim's symptoms appeared, the cause of his illness was identified, or the suit was brought. In both these kinds of case, there are wrongdoers whose allocativelyinefficient wrongdoing have caused harm and individual victims who have been harmed by the allocatively-inefficient wrongdoing of individual wrongdoers, but it is not possible to match any individual victim with the particular individual wrongdoer whose wrongdoing harmed him. In this case as well, it would be wrong as a matter of law for a court in a common-law tort suit to require injurers to pay the victims compensation that would provide potential injurers with allocatively-efficient avoidance-incentives if I am correct that judges in common-law cases are 
authorized to make only those awards that the relevant society's corrective-justice commitments warrant.

However, I do not want to proceed without mentioning another possibility that Part 3 will explore in more detail. In my judgment, even though no corrective-justice-based claim lies in this sort of case, I do think that the government of a liberal, rights-based State has an obligation to pass legislation that would require such wrongdoing possible injurers to compensate such victims of tortious wrongdoing - perhaps by making each such possible injurer liable for the share of each such victim's loss that equals the probability that he caused that loss. Even if courts are not authorized to secure this result by announcing and applying retrospectively and/or prospectively something like a market-share-liability approach to these cases, ${ }^{53}$ the victims in question may have a constitutional right that the legislature of their liberal, rights-based State give them a statutory right to recover such amounts from the wrongdoers in question and a related constitutional right to recover damages from the State if it fails to fulfill this legislative duty. Hence, even if a court was not authorized to resolve a common-law tort suit against such wrongdoing possible injurers by requiring them to compensate these victims, it might well be authorized-indeed, required-to respond to a joined constitutional claim by victims in this category to whom the State had granted no statutory right of recovery to recover their loss from the State.

The third type of causation-information whose imperfect availability can make the resolution of a common-law tort case that is correct as a matter of law allocatively inefficient is similar to the second. Assume that (1) the trier-of-fact knows that a loss might have been caused by Mother Nature alone or by a combination of Mother Nature and the choice of a particular human being or human organization and that (2) if human choice did play a role in the relevant loss' generation, the choice in question was wrongful and allocatively inefficient. Assume in addition that the trier-of-fact has imperfect information about whether human choice did play a role in the generation of the loss in question-indeed, that the only information it has on this issue is information about the contribution that the defendant's activity made to the ex ante

\footnotetext{
$53 \quad$ For a detailed discussion of the situations of this kind in which courts have and have not adopted this type of market-share-liability approach, see DAN B. DoBBS, THE LAW OF TORTS 430-32 (2000). See also RESTATEMENT

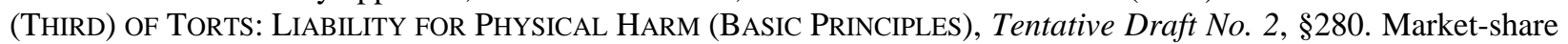
liability 103-34 and Comment o. Market-Share Liability 185-90.
} 
probability that the loss would occur. In an otherwise-Pareto-perfect world, the allocativelyefficient way for the court to respond to this sort of situation would be to hold the possible injurer liable and require him to pay the victim that percentage of the victim's loss that the possible injurer's activity contributed to the ex ante probability of the loss' occurring. However, that solution is inconsistent with the binary conception of corrective-justice rights to which we seem to be committed and which I think is consistent with if not required by liberal commitments. Under this binary conception, the possible injurer will be liable for the whole loss if his activity contributed more than $50 \%$ of the ex ante probability of its occurring and liable for none of the loss if his activity contributed $50 \%$ or less than $50 \%$ to the ex ante probability of the loss' occurring. ${ }^{54}$ In an otherwise-Pareto-perfect world, this binary response will cause misallocation in two ways:

(1) by deterring possible injurers in this position from making allocatively-efficient avoidance-moves that would reduce the contribution their activity made to the $e x$ ante probability of the loss' occurring from some higher probability not above $50 \%$ to some lower probability not above $50 \%$ and

(2) by inducing possible injurers in this position to make allocatively-inefficient avoidance-moves that reduce their activity's contribution to the ex ante probability of the loss' occurring from some probability above $50 \%$ to some probability below $50 \%$.

Some illustrations may be helpful. I start with the first possible type of misallocation. Assume that (1) the loss in question is $\$ 100,000$, (2) the probability that the loss would have incurred if the possible injurer did not avoid was $40 \%$, (3) the probability that the loss would have occurred had the defendant shut down his operations was 30\%, (4) all relevant parties are risk-neutral, and (5) the economy is otherwise-Pareto-perfect. In this initial situation, the defendant will not be liable for any loss that occurred because his activity contributed $(10 \% / 40 \%)=25 \%<50.01 \%$ of the ex ante probability of the loss' occurring-i.e., will have to reckon with paying no damages. Now assume that by spending $\$ 1,000$ the possible injurer could have eliminated his contribution to the ex ante probability of the loss' occurring. Since this avoidance-move would have reduced the weighted-average-expected loss by

\footnotetext{
54 The case law and RESTATEMENT discussion of this issue is admittedly confused and confusing. See DoBBS, op. cit. supra note 53 at 419 and RESTATEMENT (SECOND) OF TORTS §328D.
} 
$10 \%(\$ 100,000)=\$ 10,000$, it would have increased allocative efficiency by $\$ 9,000$. However, because the defendant's failure to make this avoidance-move would not have rendered him liable (because - even if it would have been detected - it could not have been shown to have been more than $50 \%$ likely to have been a but-for cause of the loss), the move would have reduced his profits by $\$ 1,000$.

The following example illustrates the second misallocative possibility. Assume that (1) the loss in question is $\$ 100,000$, (2) the probability that the loss would have occurred if the putative injurer had not avoided was $80 \%$, (3) the probability that the loss would have occurred had the possible injurer shut down his operation was $30 \%$ so that the possible injurer's activity would have contributed $(50 \% / 80 \%)=62.5 \%>50.01 \%$ of the ex ante probability of the loss' occurring if he had not avoided, (4) all relevant parties are risk-neutral, (5) the economy is otherwise-Pareto-perfect, and (6) the possible injurer could have made an avoidance-move that would have cost him $\$ 60,000$ and would have reduced the absolute amount by which his activity increased the probability of the loss' occurring from 50\% to 30\%-i.e., that would have reduced the percentage-contribution his activity made to the ex ante probability of the loss' occurring from $(50 \% / 80 \%)=62.5 \%>50.01 \%$ to $(30 \% / 60))=50 \%<50.01 \%$. On these assumptions, the avoidance-move in question would have increased the possible injurer's profits by $\$ 20,000$ since it would have cost him $\$ 60,000$ and eliminated his liability, which he would have valued at $80 \%(\$ 100,000)=\$ 80,000$ prior to his making the avoidance-move in question. Unfortunately, on these assumptions, the avoidance-move in question would have reduced allocative efficiency by $\$ 40,000$ since its allocative (as well as its private) cost was $\$ 60,000$ and its ex ante allocative benefits were $\$ 20,000$ (the product of [the $20 \%$ reduction in the probability of the loss it would effectuate] and [the loss in question-\$100,000]): the associated $\$ 60,000$ inflation in the profitability of the avoidance-move in question equals the amount by which it increased the uncompensated loss the potential victims must reckon with bearing (from $\$ 0$ of $\$ 80,000$ in weighted-average-expected losses to $\$ 60,000$ of $\$ 60,000$ in weighted-average-expected losses).

As I have already indicated, the court response that would prevent these two types of misallocation by eliminating the distortion in avoidance-incentives the current binary approach generates in these two types of situations - a rule that would hold the possible injurer liable for that percentage of the loss that his activity contributed to the ex ante probability of its occurring 
and thereby equate the amount by which the possible injurer's avoidance would reduce the damages he should expect to have to pay on the weighted average with the amount by which it would reduce the weighted-average expected loss - is incompatible with the binary conceptual corrective-justice rights with which liberalism seems to be at least compatible.

The fifth type of information whose imperfect availability can render the resolution of a common-law tort case that is correct as a matter of law allocatively inefficient is information that relates to the wrongfulness of an injurer's and/or victim's conduct. I will illustrate this possibility with three increasingly-complex examples.

The first example assumes that the trier-of-fact knows that (1) the situation in question is either an individual-care situation (one in which the most-allocatively-efficient response to the accident-or-pollution-loss contingency in question is for either the potential victim or the potential injurer to avoid) or a no-care situation (one in which the most-allocatively-efficient response to the relevant contingency is for no-one to avoid) and (2) there is a $30 \%$ probability that the potential injurer could have increased ex ante allocative efficiency while conferring a net equivalent-dollar gain on others by avoiding while there is no chance that the victim could have increased allocative efficiency by avoiding. In such a situation, transaction-cost considerations aside, it would be ex ante allocatively efficient to find the potential injurer liable since doing so would tend to induce his future counterparts to engage in allocatively-efficient avoidance when they could do so without deterring his victim's future counterparts from engaging in allocativelyefficient avoidance since ex hypothesis they cannot do so. However, in a common-law case of this kind in a liberal, rights-based State, it would not be proper for the trier-of-fact to find the injurer liable since the probability that the injurer had behaved wrongfully was not over 50\%specifically, was only $30 \%$. In this kind of situation, therefore, the State could not provide potential injurers with appropriate avoidance-incentives by “legalizing” their victims’ correctivejustice rights.

The second wrongfulness-information example extends the first to a situation in which (1) the imperfectly-informed trier-of-fact knows that the situation was either a no-care or an individual-care situation, (2) the imperfectly-informed trier-of-fact knows that there is some possibility that the victim might have been the most-allocatively-efficient potential avoider and some probability that the injurer might have been the most-allocatively-efficient potential 
avoider, and (3) the relevant probabilities enable the trier-of-fact to divide the loss in a way that guarantees that the most-allocatively-efficient avoidance-move will be made, regardless of whether the potential injurer or the potential victim is the party in a position to make it. Assume, in particular, that the trier-of-fact knows that (1) the loss is $\$ 100,000$, (2) the avoidance-moves the injurer and victim in question could have made would not have affected the sum of tort-lossrelated risk costs that would be generated, (3) the economy is otherwise-Pareto-perfect, (4) if the potential injurer can prevent the $\$ 100,000$ loss allocatively efficiently, he can do so for less than $\$ 80,000$, and (5) if the potential victim can prevent the $\$ 100,000$ loss allocative efficiently, he can do so for less than $\$ 15,000$. In this instance, any division of the loss between the potential injurer and potential victim that future counterparts of these parties can anticipate between ( $\$ 80,000$ to the injurer and $\$ 20,000$ to the victim) and (\$85,000 to the injurer and $\$ 15,000$ to the victim) will insure that allocatively-efficient avoidance-decisions will be made. By way of contrast, a loss-division of $\$ 100,000$ to the injurer and $\$ 0$ to the victim-the division that a common-law judge will be obligated to order if the trier-of-fact concludes that the probability that the injurer was negligent was higher than $50 \%$ and that the probability that the victim was contributorily negligent was not higher than 50\%-will fail to induce the victim to avoid when he is the potential most-allocatively-efficient avoider, and a loss-division of $\$ 100,000$ to the victim and \$0 to the injurer - the division that a common-law judge will be obligated to order if the trier-of-fact concludes that the probability that the injurer was negligent was not higher than $50 \%$ - will fail to induce the injurer to avoid when he is the potential most-allocatively-efficient avoider.

The third wrongfulness-information example generalizes the second still further to situations in which no loss-diversion could guarantee allocative efficiency in an otherwisePareto-perfect world because (if we assume for simplicity that the most allocatively-efficient avoidance-moves that might have been available respectively to the potential injurer and to the potential victims would have generated the same reduction in weighted-average-expected accident-or-pollution losses) the sum of (1) the highest cost that the potential injurer would have had to incur to generate that weighted-average-expected loss-reduction in the most-allocativelyefficient way it could manage and (2) the highest cost that the potential victims would have had to incur to generate that weighted-average-expected loss-reduction in the most-allocatively- 
efficient way it could manage was not lower than (3) the weighted-average-expected lossreduction either's most-allocatively-efficient avoidance-move would generate. If in such a case I assume optimistically but in no way critically (1) that the judge has information about the probability that each party will be able to generate a $\$ 100,000$ reduction in weighted-averageexpected losses by incurring avoidance-costs within each $\$ 1,000$ internal between $\$ 0-\$ 1,000$ and $\$ 99,000-\$ 100,000$ and (for convenience) (2) that any actor who will be able to avoid at a cost within a given $\$ 1,000$ interval will be able to do so at the $\$ 500$ mid-point of that interval, the judge could determine the ex ante most-allocatively-efficient loss-division by starting with a loss-division of $\$ 100,000$ to the victim and \$0 to the injurer and asking whether ex ante weighted-average-expected allocative efficiency would be increased or decreased (a) by a shift from a $\$ 100,000 / \$ 0$ to $\$ 99,000 / \$ 1,000$ victim/injurer loss-division, (b) by a shift in the lossdivision from a $\$ 99,000 / \$ 1,000$ victim/injurer loss-division to a $\$ 98,000 / \$ 2,000$ victim/injurer loss-division and so on and so forth. If for illustration we assume that there is a one-in-a-million chance-a (.0001)\% probability - that the potential victim will be able to increase ex ante allocative efficiency by $\$ 99,500$ by reducing the weighted-average-expected loss by $\$ 100,000$ at an avoidance-cost of $\$ 500$ and a one-in-a-hundred chance-a 1\% probability - that the potential injurer will be able to increase ex ante allocative efficiency by $\$ 500$ by reducing the weightedaverage-expected loss by $\$ 100,000$ by incurring $\$ 99,500$ in avoidance-costs, the net allocativeefficiency effect of shifting from a $\$ 100,000 / \$ 0$ victim/injurer loss-division to a $\$ 99,000 / \$ 1,000$ victim/injurer loss-division will be a gain of ([1\%][\$500]-[.0001\%][\$99,500]=\$5-\$.995=\$4.005). The judge would then repeat this calculation for each additional shift about which he had information and pick the loss-division that involved the total shift associated with the highest net gain. Although the loss-division that this approach reveals to be ex ante most-allocativelyefficient might be the $\$ 100,000 / \$ 0$ or $\$ 0 / \$ 100,000$ victim/injurer loss-division that corrective justice would warrant in this kind of case, I suspect that this will be true only rarely.

We have just seen that, for twelve sorts of reasons, the common-law decision that would be ex ante most-allocatively-efficient for a judge or jury to make may not be consistent with our corrective-justice commitments. In my judgment, it is not morally legitimate for judges in 
rights-based societies to decide common-law tort cases by making allocatively-efficient rulings that are not required by the relevant society’s corrective-justice commitments.

3. The Various Non-Common-Law Components of the Positive Tort Law of a Liberal, Rights-Based State: Their Moral Status (Legitimacy) and Likely Generic Desirability

Even liberal, rights-based societies that have a common law of torts will or may also have other types of tort-related law: (A) constitutional tort law, (B) legislatively-promulgated tort law that is constitutional, (C) (non-corrective-justice-based) judicially-created tort law promulgated by judges to whom legislative power has not been delegated by the legislature, (D) administrative-agency-created tort law promulgated by agency officials who have not been authorized to legislate by the legislature, and (E) (non-corrective-justice-based) new tort law promulgated by judges or administrative-agency officials who have been authorized by the legislature to create the law they promulgated. Part 3 (1) analyzes the moral status (legitimacy) of all those possible components of the tort law of a liberal, rights-based society-i.e., analyzes the relationship between such law and the society's liberal, moral-rights commitments, (2) discusses the substance of the corrective-justice-securing and non-corrective-justice-securing tort-related law a liberal, rights-based society's legislature might be obligated to enact or might properly enact, and (3) comments on the generic desirability, rights-considerations aside, of legislatures' authorizing judges and administrative-officials to promulgate tort legislation that will have only prospective application.

\section{A. Constitutional Tort Law}

In my judgment, the governments of rights-based States are obligated to make their best efforts to maximize the rights-related interests of those for whom they are responsible. This premise implies that the governments of a liberal, rights-based State are obligated not only to avoid committing torts against the moral-rights holders for whom they are responsible but also to make their best efforts (1) to minimize the extent to which their society's members and participants commit torts against each other and (2) to maximize the extent to which victims of tortious wrongdoing can obtain redress from those who have violated their tort rights (or, when these two goals cannot be achieved simultaneously, to minimize some function that equals the sum of the rights-related-interest "harm" done by tortious wrongdoing and the rights-related- 
interest "harm" done when tort victims do not have an appropriate opportunity to secure redress from their wrongful injurers).

Before proceeding, I should point out two important implications of my description of the basic obligations of the governments of any rights-based society. The first is that, in my admittedly-contestable and certainly-contested judgment, all the concrete moral and constitutional rights of the members of and participants in a rights-based society are prima facie rights in that they need not be protected if the government could protect them only by sacrificing the rights-related interests of relevant rights-holders on balance. ${ }^{55}$ Of course, in a society as wealthy as the contemporary United States, I doubt that this qualification has much practical significance - e.g., I doubt that the government will be able to justicize (render just) its failure to secure a relevant concrete tort-related right by arguing that the right's sacrifice was necessary to enable it to provide additional resources to relevant moral-rights bearers who needed them to be in a position to take their lives morally seriously (would critically affect the government's ability to make such transfers to these individuals by saving allocative transaction costs or increasing allocative efficiency in other ways). The second implication of my description of the basic obligation of a rights-based State's governments is that the governments of any rights-based State cannot justicize its failure to protect some individual's tort-related moral right when this choice will not secure relevant rights-related interests on balance by demonstrating that the choice in question would further the achievement of various perfectly-legitimate non-rightsrelated moral goals.

In short, in my judgment, the members of and participants in a liberal, rights-based society have a constitutional right that their governments make their best efforts to secure their tort-related rights in all ways that will do so without sacrificing relevant rights-related interests on balance. ${ }^{56}$ As I have already indicated, one way in which such governments can fulfill this

$55 \quad$ For my justification for this position and my response to various well-know arguments against it made by highly-respected philosophers, see Richard S. Markovits, Precommitment Analysis and Societal Moral Identity, 81 TEX. L. REV. 877, 915-21 (2003).

56 In the United States, I would deem this right to be one of the unenumerated rights to which the Eighth Amendment refers and one of the privileges or immunities to which the Fourteenth Amendment refers. Others might argue that it has a textual basis in the "due process" clauses of the Fifth and Fourteenth Amendments and is manifest in the Sixth Amendment's right to trail by jury. For an excellent, thorough account of the history of the idea in American thought that our governments are morally and constitutionally obligated to protect the moral rights that our society's members and participants have against each other, see John C.P. Goldberg, The Constitutional 
obligation is to pass legislation creating common-law courts authorized to secure the tort-related corrective-justice rights of the society's members and participants and structuring the associated legal procedures in ways that both (1) give potential plaintiffs and potential defendants appropriate access to justice and (2) make it appropriately likely that correct legal conclusions will be reached. Obviously, however, the governments of a liberal, rights-based State could also fulfill this obligation by enacting a tort statute that "legalized” its members' and participants' tort-related corrective-justice rights and provided them with appropriate opportunities to secure their legal rights. ${ }^{57}$ In addition, I suspect that the governments of a liberal, rights-based State may be constitutionally obligated to do more than merely give tort victims who have correctivejustice rights an appropriate opportunity to obtain redress by securing compensation from injurers whom they can prove more probably than not violated their rights by making choices that were the but-for cause of their loss. For example, I think that the governments of a liberal,

Status of Tort Law: Blackstone, Due Process, and the Place in Liberal Political Theory of a Law for the Redress of Wrongs (unpublished manuscript, 2005).

$57 \quad$ Although this conclusion does imply that legislation that reduces the ability of tort plaintiffs to vindicate their rights by barring recovery for pain and suffering, capping overall damage-awards, creating stricter time-limits for the filing of tort suits, capping the contingency fees that tort-plaintiff lawyers can charge, etc., may be unconstitutional, it does not imply that such legislation is unconstitutional: tort defendants have moral rights as well, and some of these reforms might be morally-acceptable responses to the tendency of triers-of-fact to make errors of various kinds that unjustly favor tort-plaintiffs. The text's conclusion also has possible implications for the constitutionality of the decision of the legislatures of a liberal, rights-based society to allow tort-liability insurance and to permit tort-related-rights violators to avoid compensating their victims by going bankrupt: This, if a liberal, rights-based society's members and participants have a rights-related interest in their wrongful injurers' compensating them and realizing no profits from their wrongdoing, tort-liability insurance would be justicizable only if it served the relevant victims' tort-related interests on balance. Tort-liability insurance also affects potential victims' tort-related rights-related interests by increasing the proportion of their losses they will be able to recover and having an uncertain effect on the amount of tortious wrongdoing that takes place in the society in question. Although it is generally assumed that tort-liability insurance encourages tortious wrongdoing by reducing the private cost to potential avoiders of rejecting avoidance-moves whose rejection will render them liable, this effect (1) is reduced by deductibles and the dependence of future premiums on past pay-outs made on behalf of the insured and (2) may be more or less offset by such insurance's possible tendency to prevent potential tortfeasors from committing torts (A) by providing them with insurance-premium data that sheds light on the tort losses for which they will be held liable if they do not change their ways (by overcoming any tendency they have to commit torts because they underestimate this figure), (B) by providing insurance companies with an incentive to condition their coverage on the insured's making certain safety-arrangements, and (C) by providing insurance companies with an incentive to do research designed to discover avoidance-moves that liberalism would require to be made once they were known. Although I have not given this issue the attention it deserves, my inclination is to conclude that it would not be permissible for a liberal, rights-based State to pass a law allowing a tortfeasor to escape liability to his victim by going bankrupt unless it simultaneously agreed to compensate the victim for his loss or at least for that part of his loss that the tortfeasor could be induced to pay. If the tortfeasor could be induced to pay some part of the loss only through methods that violated his rights, one might still say that the State should bear the loss the victim was unable to recover because the State refused to violate the tortfeasor's rights. Obviously, I recognize that this issue is difficult and that I have said little to illuminate it.

Articles/09_27_2004_Liberalism_and_Tort_Law 
rights-based State have a constitutional obligation to pass legislation that would grant two classes of victims a right to obtain compensation from wrongdoers against whom they cannot establish a corrective-justice claim:

(1) the class of individual victims whose attempts to secure compensation on a corrective-justice basis would be thwarted by their inability to identify their actual injurer-i.e., to identify the particular member of a set of wrongdoers whose wrongful choices inflicted the kind of recoverable loss the individual victim suffered on some moral-rights holders who more probably than not had harmed him—and

(2) the class of individual victims who have suffered losses that were simultaneously and independently caused by the satisfaction of two or more sets of sufficient conditions at least one of which had a member that was a wrongful choice by a moral agent..$^{58}$

More particularly, I think that the governments of a liberal, rights-based State are obligated to pass legislation that would entitle any victim in the first class to recover from each of his possible injurers a percentage of his loss equal to the probability that the injurer in question caused his loss. Relatedly, I think that the governments of a liberal, rights-based State are obligated to pass legislation that would entitle any victim in this class to collect from the wrongful choosers in question a total sum equal to his total loss. I also think that the governments of a liberal, rights-based State are obligated to pass legislation requiring the wrongful putative injurers in such cases who have not individually paid each such victim damages equal to his full loss to pay civil fines equal to the difference between the loss the victim sustained and the payment being made. ${ }^{59}$ Such legislation would have the additional advantage of preventing the loss from being distributed unfairly among the putative injurers and of deterring whipsawing tactics that may be allocatively-transaction-costly and may enable victims to secure payments to which they are not morally entitled.

58 Admittedly, no-one has a right to be compensated by wrongdoers whose wrongful choices turn out not to "cause" (on any construction of "cause”) harm (other than the "abstract" harm that wrongful choices generate by showing disrespect for all their potential victims). However, it does not seem to me that someone whose wrongful choice was a necessary element of a set of sufficient conditions for a loss' occurring all of whose members were fulfilled is entitled to his moral luck-i.e., to benefit from the fortuity that the loss with his choice was associated would have occurred had he not made a wrongful choice that guaranteed its occurrence.

$59 \quad$ Admittedly, it might be appropriate to adjust the civil fines in question to reflect the fact that the relevant putative injurer's avoidance-incentives were distorted by other Pareto imperfections. 
The governments of liberal, rights-based States are also morally obligated to prevent tortious wrongdoing by socializing its members and participants to treat each other with appropriate, equal respect and concern and providing them with the intellectual skills needed to make non-tortious choices.

Finally, the governments of liberal, rights-based States may also be morally and hence constitutionally obligated to pass legislation (1) to secure allocatively-efficient and/or life-ofmoral-integrity-opportunity-enhancing outcomes in the type of step-function loss cases previously analyzed and (2) to prevent mere-utility losses from being generated allocatively inefficiently or life-of-moral-integrity opportunities from being lost because relevant actors are misinformed. In particular, the governments of a liberal, rights-based society will be obligated to pass such legislation when the preventable loss was a mere-utility loss unless its decision could reasonably have been thought to have been rendered morally desirable by its tendency to promote some legitimate, non-liberal distributive goal or some other type of defensible, nonliberal social goal more beneficially than it could in any other way, and the governments of a liberal, rights-based society will be obligated to pass such legislation when the preventable loss was opportunity-to-lead-a-life-of-moral-integrity-related unless its decision secured rightsrelated interests on balance (in comparison with the most-rights-related-interest-securing set of policies it could have adopted).

The point of this section is that, if the legislatures of a liberal, rights-based State fail to make their best efforts to secure the liberal, tort-related corrective-justice rights and rightsrelated interests of their society's members and participants by passing legislation, conceivably by authorizing administrative agencies to pass appropriate legislation, and by supervising the way in which judges and administrative hearing officers apply the law, individual moral rightsholders whose tort-related rights have been sacrificed by these government failures will have a moral right to receive compensation from the government-a moral right whose constitutional counterpart would in principle be judicially enforceable, though in some instances imperfections in the information available to courts would lead them to be underenforced.

\section{B. Legislatively-Promulgated Tort Law and Tort-Related Law That Is Constitutional}


Tort law is the body of law that protects interests not protected by contract law or property law. Conventionally, tort law includes not only (1) law that gives legal effect to victims' tort-related corrective-justice rights but also (2) law that is designed to prevent the kinds of concrete losses that tortious wrongdoing can generate or to grant their victims the legal right to obtain compensation for such losses even when those losses are caused by human choices that are not wrongful. This section is concerned not only with tort law in this broader sense but also with what might be called "tort-related law:" (1) law that is designed to decrease the allocative transaction cost of securing tort-related corrective-justice rights to any given extent, (2) law that is designed to increase the accuracy of the resolution of corrective-justice-based tort suits, (3) law such as bankruptcy law that is designed to secure a mixture of allocative-efficiency and noncorrective-justice distributive goals that cannot be fully achieved without sacrificing tort-related interests (though the State can reduce and may be constitutionally obligated to reduce the disservice these laws do to such interests by compensating the bankrupt's tort victims itself), (4) law that is designed purely to effectuate non-corrective-justice distributive norms, ${ }^{60}$ which may or may not disserve the corrective-justice interests of victims of tortiously-wrongful conduct and that therefore may or may not have to be combined with a State program to compensate the corrective-justice right-holders the primary policy harmed, and (5) law that is designed to further the parochial interests of its supporters-law that may or may not (fortuitously) be desirable from any defensible normative perspective and that may be unconstitutional on that account, regardless of whether it disserved any tort-related interest that is constitutionally protected. I have included this section for two reasons: (1) to acknowledge that the body of law conventionally called tort law and a fortiori the body of law that I am calling tort-related law contain law that is not designed solely to secure the corrective-justice and corrective-justicerelated rights of actual and potential tort victims and (2) to set up the remaining sections of Part 3 , which focus on the moral status (inter alia, the moral permissibility) and likely generic desirability (rights-considerations aside) of tort law that is not created by common-law courts or legislatures that are exercising their respective authorities.

$60 \quad$ For an explanation of why such laws may be the most desirable way to effectuate such norms, see Richard S. Markovits, Why Kaplow and Shavell's “Double-Distortion-Argument” Argument Is Wrong, GEO. MASON L. REV. (2004). 
C. Non-Corrective-Justice-Based Tort Law Created by Judges Whom the Legislature Has Not Authorized to Exercise Legislative Power

Many contemporary law professors and a significant number of contemporary judges are moral-rights skeptics - indeed, dismiss moral-rights discourse as mumbo-jumbo. Some who take this position do believe in the coherence of legal argument-indeed, believe that legal argument can yield unique, correct answers to all legal-rights questions, but their view of the set of legal arguments that can produce such answers represents law as an arcane practice in which moralrights considerations play no role. However, most contemporary law professors and judges who are moral-rights skeptics do not believe that legal argument can generate unique answers that are right as a matter of law and maintain that judges should decide cases to promote various nonmoral-rights-related goals-i.e., should operate as social engineers. Many tort scholars and judges belong in this latter group. Some such as Professor Fleming James and Judge Roger Traynor recommend that judges resolve common-law tort cases in the way the would maximize the extent to which the loss is spread. ${ }^{61}$ Others such a Professor William Prosser recommend that judges resolve common-law tort cases in the way that will produce "the greatest happiness for the greatest number." ${ }^{62}$ And still others such as Professor (now Judge) Richard Posner argue that such cases should be decided in the way that maximizes economic efficiency. ${ }^{63}$

I began this section with the preceding paragraph to forestall the reaction that no-one would think that it was morally permissible or desirable for judges to usurp legislative power by creating truly-new law (which did not secure the plaintiff's right to corrective justice) that would promote some arguably-desirable social goal. If my non-systematic experience is a reliable guide, this reaction is mistaken-many contemporary law professors think that judges should act as social engineers.

In my view, in any type of rights-based State, it would be morally impermissible for judges who have not been authorized to legislate by the legislature or the People to promulgate

61 For an account of James’ position, see John C.P. Goldberg, Comment: Misconduct, Misfortune and Just Compensation: Weinstein on Torts, 97 Colum. L. REV. 2034, 2045-50 (1998). For Traynor's position, see Roger J. Traynor, The Ways and Meanings of Defective Products and Strict Liability, 32 TENN. L. REV. 363, 366, 369, 37576 (1965). These cites are taken from Goldberg, op. cit. supra note 56 at n. 382.

62 William L. Prosser, HandBoOK OF THE LAW OF TORTS $\S 3$ at 15, 17 (1st ed. 1941).

63 Richard A. Posner, Same Uses and Abuses of Economics in Law, 46 U. CHI. L. REV. 281, 287 (1979). 
new law to achieve the social good even if they applied the new law they promulgate only prospectively. Moreover this conclusion would hold a fortiori for such judges' usurping the power to create such truly-new law and then applying it retrospectively as well as prospectively.

Regardless of the moral norm from which a given society derives its moral-rights conclusions, usurpations of political power violate the moral rights of the individuals who have the right to exercise or delegate that power. In a liberal, rights-based society (which is committed to treating all its members with appropriate, equal respect and concern), the empowered group consists of all society-members who have the capacity to make the relevant choices in a minimally competent fashion. This conclusion is a corollary of the basic duty such a society is committed to fulfilling since that duty requires that each member of such a society have an equal, appropriate opportunity to be the author of the laws that will govern him (an admittedly-hard-to-operationalize concept that I believe is clearly violated by usurpations of political power). ${ }^{64}$

Moreover, if judges apply retrospectively any truly-new law they create, their decision to do so will fail to show the respect that is owed the loser of the case in question by subjecting him to ex post facto legislation: even if such judicially-created legislation is not designed to punish personal or political enemies or to deter personal or political opposition, it disrespects its victims by failing to give them fair notice of the law they will be sanctioned for violating.

I should add that, for at least three reasons, even if judicial usurpation of socialengineering power were morally permissible in a liberal, rights-based State (i.e., did not violate the usurping judges' obligations and the rights of "the People”), it would probably be generically a bad idea. First, the training and professional experience of judges, the staffs that are available to them, and the decisionmaking procedures they are constrained to use make it less likely that they will perform social-engineering functions better than will legislatures or administrative

64 Admittedly, one might argue that, given the reality that our actual political system falls far short of instantiating this liberal political-opportunity norm, judicial usurpation of political power might equalize the opportunity of society-members to influence the laws that will govern them because the individuals who have a higher-than-average ability to influence judicial social engineering have a lower-than-average ability to influence legislative and executive-branch social engineering. I question the accuracy of this empirical premise, am confident that its accuracy would decline if judges engaged more in social engineering, and have doubts about the legitimacy of taking this type of second-best approach to rights-violations: am inclined to think that-when political arrangements violate participation rights and increase on this account the probability that outcome-rights will be 
agencies. Although many of the courses that students take in law school expose them to moralrights and other sorts of normative analyses even when taught by professors who claim that such analyses have no role to play or do not play an important role in legal argument and lawyers in their professional practices often make arguments that are either explicitly normative or are based on moral understandings (e.g., arguments about whether historical argument should be broad-gauged or narrow-gauged), law schools do not train people to be social engineers and (I suspect) would be unlikely to do so as well as the public-policy schools, economics departments, and sociology departments that are increasingly likely to have trained administrative-agency personnel even if judges engaged in a lot more social engineering than they do at present. Although the preceding comparative disadvantage of judges might be offset in the short run by the lower likelihood that they would be "politically corrupt" in both a narrow and broad sense of that expression, I expect that any corruption advantage would diminish through time if judges increasingly performed a social-engineering role since this change in role would lead to changes in the kind of people who compete for judgeships and the processes through which and criteria by which judges are selected. Second, at least if one believes that there are internally-right answers to some tort-law questions and that cases in which such answers exist should be controlled by them, there is a risk that judges who choose to legislate in cases in which the only answer that is right as a matter of law is the rule that a plaintiff loses if he cannot establish more than a $50 \%$ probability that he is legally entitled to a verdict in his favor may choose to ignore the answer that is correct as a matter of law in cases in which the plaintiff or defendant can establish his legal right when the judge considers that internally-right answer to the legal-rights question to be wrong as a matter of policy. Third, if one thinks that rights-based societies of moral integrity are more morally desirable than goal-based societies of moral integrity, judicial usurpations of legislative power will also tent to be generally undesirable to the extent that they undermine the public's consciousness of the distinction between the right and the good and derivatively its rights-commitedness.

D. Tort Law Created by Administrative-Agency Officials Who Have Not Been Authorized by a Legislature or the People to Perform This Function

violated as well—rights-based societies must respond by eliminating "imperfections" rather than introducing offsetting imperfections.

Articles/09_27_2004_Liberalism_and_Tort_Law 
I want to make five points about such law. First, in a rights-based society, administrative-agency usurpation of legislative power is equally-rights-violate as judicial usurpation of legislative power. Second, if administrative "regulations" truly do create new law, the retrospective application of such new law will be equally-rights-violative as the retrospective application of judicially-created new law. Third, the formal training and professional experience of administrative-agency officials, their ability to specialize, the staff that is available to them, and the procedures that they can use to create new law give them a comparative advantage over judges and possibly over legislatures at engaging in social engineering. Fourth, the specialization of administrative agencies may make them more vulnerable to capture than either legislatures or courts of general jurisdiction. And fifth, the concern that judges who are also supposed to adjudicate cases that raise issues for which there are internally-right answers will be less likely to perform this function properly if they act as social engineers in other situations will be equally salient in the administrative-agency context only if the agency officials who engage in social engineering are administrative hearing officers-i.e., only if within the agency the legislative and adjudicatory roles are not assigned to different personnel and institutions.

E. Non-Corrective-Justice-Based Tort Law Created by Judges or Administrative-Agency Officials to Whom the Legislature Has Delegated Such Power

Legislative redelegations of legislative power to judges or administrative-agency officials raise only one issue not already considered: the moral permissibility and related constitutionality of the redelegation itself in a rights-based society. Regardless of whether it would be wise for them to do so, I suspect that it would not be morally impermissible for the members of a liberal, rights-based society to authorize state officials who also function as judges or administrative interpreters and appliers of legislation to promulgate new law that would apply exclusively prospectively. However, although the American public appears to have acquiesced to its legislatures' redelegating their legislative power to administrative agencies, I do find such redelegations morally problematic in rights-based societies if they are not explicitly authorized by the People regardless of whether the delegation is to an administrative-agency official or a judge and doubt that such redelegations can be legitimated ex post by considered social 
acceptance even if that acceptance takes the form of an explicit vote on the redelegation in question.

\section{CONCLUSION}

Virtually all academic analyses of the relationship between "morality" and the content of American tort law take one of four tacks that I find unsatisfactory. Some such analyses claim that moral argument of any type is irrelevant to the determination of the answer to any tort question that is correct or a matter of law. I find this approach unsatisfactory because it is inconsistent with the combination of the fact that the United States is a rights-based State of moral integrity and the axiom that, to be morally legitimate, both legal argument in a given society and the law of that society must be consistent with the society's moral commitments. Other analyses claim that moral argument is relevant to the determination of the internally-right answer to any tort-law question only if the relevant moral principle is explicitly approved in the case-law or cited by some applicable statute (or perhaps provides the best account of the conclusions reached in the relevant cases or explicitly mandated by the relevant statute). I find this approach unsatisfactory not only because-since Lochner ${ }^{65}$-American judges have hesitated to include reference to moral principles in their opinions but, more fundamentally, because it assumes that legal practice is self-legitimating (because it ignores the fact that even a consistent legal practice can be morally illegitimate and legally invalid if it is inconsistent with the moral commitments of the society in question [because it ignores the fact that, although a society's legal discourse, conduct, and perceptions from part of the data-base from which one must determine its moral type, moral character, and specific moral commitments, such legal data form only a small part of the relevant data-base, which primarily consists of data on the society's members' prescriptive-moral discourse, conduct, and perceptions outside of legal fora]). Two other sets of tort-law scholars contend that moral argument is relevant to the determination of the answer to a tort-law question that is correct as a matter of law even when the moral argument in question has never been used by a judge in a tort-law case or referenced by a statute-indeed, claim that moral argument is not only relevant to the determination of the internally-right answer to tort-law questions but determines the internally-right answer to all or at least some such 
questions. One set of such scholars think that the type of moral argument that plays this determinative role is purely-conceptual, so-called foundationalist argument from which one can derive objectively-true, universally-applicable norms of justice that determine the right answer to all tort-law questions. I reject this approach partly because I have never been convinced by any such foundationalist argument and partly because much statutory tort law is not designed to effectuate justice-is designed not to secure the corrective-justice interests of relevant moralrights holders but to achieve various defensible social goals or the parochial interests of its supporters. The other set of such scholars think that the type of moral argument that controls the internally-right answer to tort-law questions or the answer that should be given to such questions (1) given that there never is an internally-right answer to any question of law or (2) when there is no internally-right answer to a particular question of tort law is an argument that derives it conclusion from a moral norm whose instantiation the author favors but whose objective moral superiority or optimality (he admits) cannot be established. I reject this approach for three reasons: (1) because I believe that there are internal-to-law correct answers to all tort-law questions in the United States, (2) because I believe that the response that is the internally-right response to a tort-law claim in the United States that is based on the plaintiff's corrective-justice and corrective-justice-related rights is the response that is required by the American commitment to protecting liberal moral rights_-a commitment that must be inferred from a philosophicallyinformed empirical analysis of our society’s members' and governments' prescriptive-moral discourse, conduct, and perceptions and that may require legal outcomes that are inconsistent with those favored by the relevant scholar's preferred personal value, and (3) because I believe that the response that is the internally-right response to a tort-law claim in the United States that is based on a statute that does not violate any affected party's moral rights and is designed to secure some defensible social goal or the parochial interests of its supporters is (roughly speaking) the response that will most further that social goal or those interests, which may also not be the response favored by the relevant scholar's preferred personal value.

This Article proceeds from different conclusions about the relevance of moral argument to the determination of the internal-to-law correct answer to tort-law questions in different societies. It begins by distinguishing between two types of prescriptive-moral argument-moral-

65 Lochner v. New York, 198 U.S. 45 (1905).

Articles/09_27_2004_Liberalism_and_Tort_Law 
rights arguments about the just (which derive their conclusions from moral norms I call "moral principles”) and moral-ought arguments about the good (which derive their conclusions from moral norms I call "personal ultimate values”). It then argues that, although some societies do not draw a strong distinction between these two types of argument, other societies (so-called rights-based societies) do. After that, it develops a protocol for determining whether a society is a rights-based society or a goal-based society and another protocol for identifying the moral norm that any society of either type is committed to instantiating. Next, it asserts that the United States is a liberal, rights-based society of moral integrity and delineates (1) the basic obligation of such a society's members, participants, and governments and (2) the more concrete tortrelated corollaries of that basic obligation. In the course of executing these last analyses, the Article explains (1) why the common law of torts of any liberal, rights-based society that has common law will be exclusively concerned with protecting the liberal tort-related correctivejustice and corrective-justice-related rights of its members and participants, (2) why a liberal, rights-based society that does not fully secure its members' and participants' tort-related rights through the common law is constitutionally obligated to do so statutorily, (3) why a liberal, rights-based State’s corrective-justice-securing tort law may not be allocatively efficient, (4) why a liberal, rights-based State may be morally and constitutionally obligated to protect its members and participants from losses that they cannot recover in contract law or property law when they also cannot establish or do not have a corrective-justice tort claim for compensation, (5) that a liberal, rights-based State may legitimately respond to loss-contingencies in ways designed to achieve various non-corrective-justice goals so long as their efforts to do so do not sacrifice rights-related interest on balance, (6) that decisions by judges in rights-based States to create non-corrective-justice-securing tort law are morally impermissible and hence unconstitutional absent authorization from the legislation or the People, morally impermissible and hence unconstitutional even if authorized if the new law is to be applied retrospectively, and generically of dubious desirability, moral rights and constitutional considerations aside, (7) that decisions by administrative-agency officials to create tort law are morally impermissible and hence unconstitutional if not authorized by the legislature or the People, and (8) that legislative decisions to redelegate the legislative power given them by the People to judges or 
administrative-agency officials are morally and hence constitutionally dubious absent an explicit ex ante vote of the People authorizing such redelegations. 